\title{
Surrogate markers predicting overall survival for lung cancer: ELCWP recommendations
}

\author{
T. Berghmans, F. Pasleau, M. Paesmans, Y. Bonduelle, J. Cadranel, I. Cs Toth, \\ C. Garcia, V. Giner, S. Holbrechts, J.J. Lafitte, J. Lecomte, I. Louviaux, E. Markiewicz, \\ A.P. Meert, M. Richez, M. Roelandts, A. Scherpereel, Ch. Tulippe, P. Van Houtte, \\ P. Van Schil, C. Wachters, V. Westeel and J.P. Sculier
}

\begin{abstract}
The present systematic review was performed under the auspices of the European Lung Cancer Working Party (ELCWP) in order to determine the role of early intermediate criteria (surrogate markers), instead of survival, in determining treatment efficacy in patients with lung cancer. Initially, the level of evidence for the use of overall survival to evaluate treatment efficacy was reviewed. Nine questions were then formulated by the ELCWP. After reviewing the literature with experts on these questions, it can be concluded that overall survival is still the best criterion for predicting treatment efficacy in lung cancer. Some intermediate criteria can be early predictors, if not surrogates, for survival, despite limitations in their potential application: these include time to progression, progression-free survival, objective response, local control after radiotherapy, downstaging in locally advanced nonsmall cell lung cancer (NSCLC), complete resection and pathological TNM in resected NSCLC, and a few circulating markers. Other criteria assessed in these recommendations are not currently adequate surrogates of survival in lung cancer.
\end{abstract}

KEYWORDS: Guidelines, lung cancer, surrogate, survival, systematic review

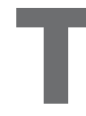
he European Lung Cancer Working Party (ELCWP) is a cooperative research group that has been actively involved in the performance of academic clinical trials in thoracic oncology for more than 30 yrs. Published reports on trials, performed in various stages and with various histological types of lung cancer, can be found at the ELCWP website (www.elcwp.org). The group is also involved in evidence-based medicine and has published a number of metaanalyses and systematic reviews [1], as well as guidelines on the management of small (SCLC) and nonsmall cell lung cancer (NSCLC) [2-6].

Improvement in survival or cure rates is the main therapeutic goal in lung cancer management. Other criteria of efficacy are commonly used as primary end-points in clinical studies and randomised trials, mainly concerning disease control (duration and response) and quality of life (QoL) or symptom control. During the past decade, new techniques have emerged that have had some impact on the therapeutic approach to lung cancer, such as integration of positron emission tomography into the staging strategy or use of tissue and blood biomarkers for predicting survival prognosis or treatment efficacy. The aforementioned intermediate criteria have been proposed by some researchers for use as primary efficacy criteria in lung cancer. Nevertheless, it is currently not clear whether these criteria can correctly predict overall survival.

Intermediate criteria could provide some advantages by replacing final end-points in clinical trials. They can occur more frequently or sooner than disease-specific mortality or overall survival. The term "surrogate" is generally used in an informal way to indicate that a biomarker or an intermediate end-point can be used instead of the final end-point of interest. A definition of surrogacy was proposed 20 yrs ago by PRENTICE [7],
AFFILIATIONS

For authors' affiliation details, please refer to the Acknowledgements section.

\section{CORRESPONDENCE}

T. Berghmans

Service des Soins Intensifs and

Oncologie Thoracique,

Institut Jules Bordet

Centre des Tumeurs de l'Université

Libre de Bruxelles (ULB)

1 rue Héger-Bordet

B-1000 Bruxelles

Belgium

E-mail: thierry.berghmans@

bordet.be

Received:

Dec 102010

Accepted after revision:

May 292011

First published online:

July 072011 
who has also defined operational criteria for validating the value of a candidate surrogate: 1) a treatment should impact both on the candidate surrogate and on the true clinical end-point; and 2) the treatment effect on the surrogate should fully capture the treatment effect on the true end-point. As this second condition is difficult to prove and not practically suitable, other definitions have emerged. As mentioned by BUYSE et al. [8], a general consensus now exists that the validation of a surrogate end-point can be carried out on the basis of a correlation approach: first, a correlation should be demonstrated at the individual level; that is, the surrogate end-point has to be shown to be predictive of the true outcome; secondly, a correlation should be obtained at the trial level (a correlation that can be assessed through meta-analytical techniques). Nevertheless, showing surrogacy remains a difficult exercise. As we expected to find only scarce demonstrations of surrogacy in the field of lung cancer, we searched for intermediate markers that are "simply" predictive/prognostic of the true outcome. Therefore, we avoid in the present report the use of the term surrogate/ surrogacy and instead use the term "predictive", "prognostic" or "early" marker of treatment effect.

The following guidelines have been developed by the ELCWP in order to determine if intermediate criteria can be used as adequate predictive markers of overall survival in patients with lung cancer. The main target of our group is to help clinicians involved in the treatment of patients with lung cancer to integrate study results from the literature into their routine practice.

\section{METHODOLOGY}

A preliminary symposium dedicated to this topic was held in Brussels, Belgium, with the participation of a panel of experts (10th Annual Day of Thoracic Oncology; March 21, 2009). This led the ELCWP to make recommendations on the value of intermediate criteria for predicting survival in lung cancer. Initially, the level of evidence for the use of overall survival to evaluate efficacy was reviewed. Furthermore, the guidelines aimed to answer the following nine questions. 1) Can the criteria of progression-free survival (PFS), time to progression (TTP) and disease-free survival (DFS) be used to assess overall survival? 2) Is objective morphological response to chemotherapy a valid efficacy criterion, and which evaluation criteria for response are to be used? 3) Are objective morphological response criteria and local control applicable for the assessment of overall survival in the case of chemoradiotherapy (either sequential or concomitant)? 4) Can quality of life criteria be used to predict overall survival, and which quality of life scoring system should be applied? 5) Can downstaging after induction chemotherapy predict overall survival, and which assessment methodology needs to be used? 6) Do complete resection and pathological TNM have a predictive role for survival? 7) Can metabolic response, assessed by ${ }^{18} \mathrm{~F}$-fluorodeoxyglucose gathering on positron emission tomography $\left({ }^{18} \mathrm{~F}-\mathrm{FDG}\right.$-PET or PET-CT), predict the efficacy of chemotherapy? 8) What is the role of tissue biological markers for the evaluation of overall survival? 9) What is the role of circulating markers (molecules or cells) for the assessment of overall survival? For each question, a definition of the intermediate criteria is provided.

A review of the literature was performed using the Ovid Medline system. This research was performed by a scientific librarian, experienced in searching for medical and scientific publications, and by physicians, experts in the treatment of thoracic neoplasms and trained in evidence-based medicine, assisted by a biostatistician.

Ovid Medline was searched using the OvidSP interface. Unless otherwise stated, search terms were $\mathrm{MeSH}$ terms (medical subject headings). MeSH terms were also combined with relevant free-text terms that were searched for in all of the fields containing text words, particularly in titles and abstracts. The "PICO" (population, intervention, comparator, outcome) model for clinical questions was used to isolate the concepts included in the question [9]. The corresponding search criteria were translated into $\mathrm{MeSH}$ terms and free-text keywords (online supplementary material). Completed search strategies included the " $\mathrm{P}$ " and " $\mathrm{O}$ " criteria combined with one of the possible intermediate markers listed in the online supplementary material. Results were limited to those published in the period 1986 to March 2010, except when the demonstration of overall survival required retrieval of old surgical series or randomised trials in SCLC. When the number of retrieved citations was too large, additional limits were applied according to publication types and levels of evidence, with randomised controlled trials and metaanalyses having the strongest levels of support. In a few cases, it was also necessary to reduce background noise by excluding studies focused on secondary lung cancers. Citations were exported from Medline into reference manager databases to allow the removal of duplicates and to facilitate the next selection by reviewers. Exported references were scanned for relevance. Articles were rejected on initial screening when titles, abstracts and $\mathrm{MeSH}$ terms did not meet the inclusion criteria. The remaining articles were evaluated further for inclusion in the current review. This search was supplemented by screening the references of the selected articles and other literature known by the research team and the ELCWP members.

To be eligible, a study had to fulfil the following criteria: to be dedicated to the study of primary lung cancer, whatever the stage or the histology; to deal with tumour staging, at least for most of the patients included in the study, using the fourth, fifth or sixth edition $[10,11]$ of the international staging system, except for SCLC; to assess the relationship between one of the intermediate criteria selected for the guidelines and survival, at least in univariate analysis, whether it was the primary objective of the publication or not; to be published in the English, French, German or Dutch language literature, accessible to all coauthors. Abstracts were excluded as they cannot be expected to provide enough detail to allow the assessment of methodology and/or survival information. However, we allowed the consideration of unpublished studies if detailed results and methodology allowing adequate interpretation for the current guidelines were available, for example, an extensive oral presentation on the website of a congress.

The recommendations were graded according to the Grades of Recommendation Assessment, Development and Evaluation (GRADE) system [12]; the methodology is summarised in table 1. Selection of the publications was made according to this system. The best level of evidence was systematically looked for. The search was first limited to meta-analyses and randomised controlled trials; if none was available, we looked for casecontrol, cohort or prospective studies; finally, case reports, case 


\section{TABLE 1 Grades of Recommendation Assessment, Development and Evaluation system}

\section{First step: quality of evidence and definitions}

\section{High quality}

Further research is very unlikely to change our confidence in the estimate of effect

\section{Moderate quality}

Further research is likely to have an important impact on our confidence in the estimate of effect and may change the estimate

2. Low quality

Further research is very likely to have an important impact on our confidence in the estimate of effect and is likely to change the estimate

1. Very low quality

Any estimate of effect is very uncertain

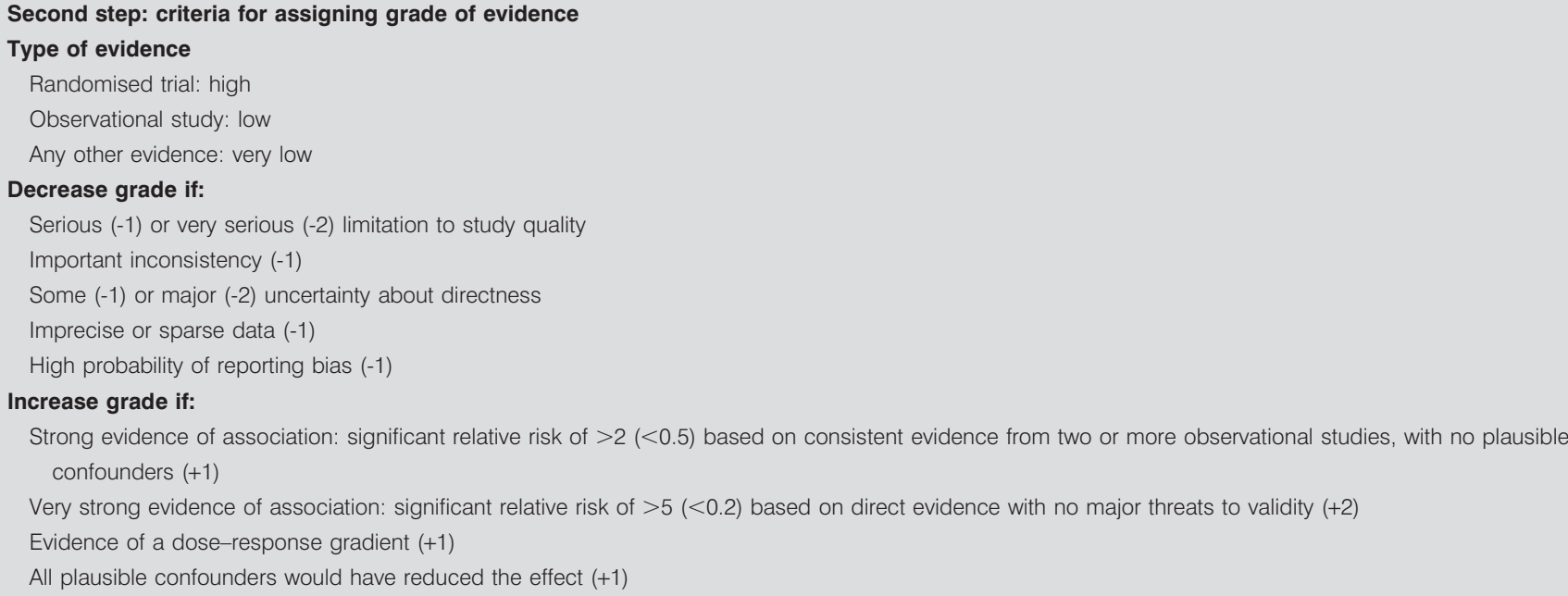

\section{Third step: strength of recommendation}

Fs: strong recommendation for using an intervention

Fw: weak recommendation for using an intervention

Aw: weak recommendation against using an intervention

As: strong recommendation against using an intervention

Determinants of strength: balance between desirable and undesirable effects; quality of evidence; values and preferences; costs (resource allocation)

Modified from [12] with permission from the publisher.

series and expert opinion were considered. We graded the recommendations as strongly or weakly, for or against using an intervention. When no data were available to answer a question, we decided that the recommendation was against the use of the intervention.

A draft was written and discussed during three workshops of the ELCWP (March 28 and October 16, 2009, and April 16, 2010) by all the co-authors who reviewed the evidence found in the literature. Thereafter, the guidelines were reviewed by the ELCWP at a meeting held in Brussels in November 2010 and approved by the panel of experts. The authors included medical oncologists, thoracic surgeons, pneumologists, radiation oncologists and methodologists involved with the management of thoracic malignancies (target audience) as recommended by the AGREE collaboration group for the evaluation of guideline quality (www.agreecollaboration.org). Remarks and suggestions were then integrated into the final version of the guidelines. The level of evidence, quality of evidence and grade of recommendation are listed in table 2.

\section{PRELIMINARY QUESTION: THE USE OF OVERALL SURVIVAL TO EVALUATE TREATMENT EFFICACY}

According to the US Food and Drug Administration [13], survival is defined as the duration between registration or randomisation in a study and death from any cause (measured in intent-to-treat). Cure is more difficult to define. The World Health Organization (WHO) proposed a definition based on survival duration in the group of patients with the disease, in comparison to that observed in a general population with comparable demographic criteria but without the disease [14]. Another option is to consider that the patient is cured when he survives in good health for a sufficient length of time comparable to that of a group of patients with known low probability of recurrence.

The assessment of survival as a marker of treatment efficacy in lung cancer patients can be evaluated in five instances: resectable NSCLC, unresectable non-metastatic NSCLC, advanced and metastatic NSCLC, and limited and extensive disease SCLC. This evaluation is based on the review of the literature performed by the ELCWP (www.elcwp.org) [2-6]. 


\section{TABLE 2 Summary of the recommendations based on level of evidence, quality of evidence and grade of recommendation (Grades of Recommendation Assessment, Development and Evaluation system)}

$\begin{array}{ccc}\begin{array}{c}\text { Level of } \\ \text { evidence }\end{array} & \begin{array}{l}\text { Quality of } \\ \text { evidence }\end{array} & \begin{array}{c}\text { Grade of } \\ \text { recommendation }\end{array}\end{array}$

1.1) Time-to-progression is an intermediate marker for overall survival in advanced NSCLC treated with first-line chemotherapy

1.2) Progression-free survival is a potential intermediate marker for survival in the setting of docetaxel or vinca-alcaloids first-line based regimens

2.1) Objective response is an intermediate criterion for overall survival in advanced NSCLC treated with first-line or salvage chemotherapy

2.2) Objective response is an intermediate criterion for overall survival in extensive disease SCLC treated with first-line chemotherapy

2.3) Objective response is a potential intermediate criterion for overall survival in operable NSCLC treated with induction chemotherapy and in locoregionally advanced NSCLC treated by chemotherapy and radiotherapy

3.1) Although commonly used, conventional criteria for response assessment of primary lung tumour treated by (chemo)radiotherapy cannot be used as intermediate criteria for survival

3.2) Local control, for which the definition has to be clarified, may be a possible intermediate criterion for overall survival

4) Response at the QoL level cannot be recommended as an intermediate criterion for overall survival due to a lack of robust data

5) Although not strictly demonstrated, there are numerous arguments from subgroup analyses of randomised trials and retrospective studies that mediastinal downstaging and, to a lesser extent, TN downstaging are associated with better survival in locally advanced NSCLC treated by induction chemotherapy or chemoradiotherapy before surgery

6.1) Complete resection is a prognostic factor for survival in resected NSCLC and can be used as an intermediate criterion for overall survival

6.2) Pathological TNM is a prognostic factor for survival in resected NSCLC and can be used as an intermediate criterion for overall survival

7) Metabolic response assessed by PET scan should not be used for the routine assessment of response to treatment in lung cancer patients in place of morphological criteria

8) Tissue biological markers have not to be used for evaluation of treatment efficacy and are not adequate intermediate criteria for overall survival in lung cancer patients

9.1) It is suggested that some circulating markers (CEA, Cyfra 21-1 and pro-GRP, and to a lesser extent NSE, CA-125 and CA19-9), used as single criterion to assess overall survival, could be adequate intermediate criteria for survival in lung cancer patients

9.2) The persistence of circulating tumour cells in NSCLC may have a prognostic impact on further survival

\begin{tabular}{|c|c|c|}
\hline MA & 3 & Fs \\
\hline MA & 2 & $\mathrm{FW}$ \\
\hline MA/RT & 4 & Fs \\
\hline MA/ReS & 2 & Fw \\
\hline ReS & 2 & Fw \\
\hline ReS & 1 & Aw \\
\hline ReS & 1 & Fw \\
\hline ReS & 1 & Aw \\
\hline ReS & 2 & FW \\
\hline Cohort/ReS & 3 & Fs \\
\hline Cohort & 3 & Fs \\
\hline ReS/CS & 1 & Aw \\
\hline CS & 1 & Aw \\
\hline ReS & 2 & $\mathrm{FW}$ \\
\hline Cohort & 1 & FW \\
\hline
\end{tabular}

NSCLC: nonsmall cell lung cancer; SCLC: small cell lung cancer; QoL: quality of life; PET: positron emission tomography; CEA: carcinoembryonic antigen; pro-GRP: pro-gastrin releasing peptide; NSE: neurone-specific enolase; MA: meta-analysis; RT: randomised trial; ReS: retrospective studies; CS: case series; Fs: strong recommendation for using an intervention; Fw: weak recommendation for using an intervention; Aw: weak recommendation against using an intervention

1) For obvious ethical reasons, no randomised trials have been performed comparing surgery alone to another medical treatment or no therapy in operable patients with resectable NSCLC. The level of evidence that surgery improves overall survival and curability is based on historical data from retrospective and prospective surgical series [15]. In accordance with other guidelines, surgery is the treatment of choice for stage I and II diseases and remains an option for stage III NSCLC. Randomised trials and meta-analyses have demonstrated that adjuvant and, to a lesser extent, induction cisplatin-based chemotherapy, as well as UFT (Uracil-Tegafur) in Japanese patients, prolonged survival in comparison with surgery alone, at least in stage II and III NSCLC $[16,17]$.
2) The evidence of the curative role of radiotherapy alone for unresectable non-metastatic NSCLC comes from control arms of randomised trials of treatment with irradiation alone or by extrapolation from series of inoperable patients with resectable NSCLC (stages I and II). A 5-yr survival of $4-10 \%$ was documented $[18,19]$. The addition of chemotherapy to curative radiotherapy, administered either sequentially or concomitantly, yielded improved survival and cure rates in comparison with those for radiotherapy alone. This evidence came from randomised trials and meta-analyses [20-25].

3) At least 15 randomised trials and five meta-analyses confirmed that survival improvement is obtained with first-line 
chemotherapy in comparison with best palliative care alone in advanced and metastatic NSCLC [20, 26-29]. Two randomised trials demonstrated that salvage chemotherapy with docetaxel or erlotinib also improved survival in comparison with palliative care $[30,31]$.

4) The effect on survival of chemotherapy for first-line treatment of SCLC was first observed in old randomised trials comparing alkylating agents with inert compounds, which showed improved survival with cyclophosphamide monotherapy [32]. Currently, multiple drug administration has become the standard chemotherapy. In this instance, two meta-analyses demonstrated that cisplatin- and/or etoposide-based chemotherapy is more effective and yielded better survival than other regimens [33, 34]. In limited disease SCLC, 15 randomised trials and three metaanalyses demonstrated that the addition of radiotherapy to chemotherapy increased survival in comparison with chemotherapy alone [35-37]. There has been only one randomised trial comparing topotecan with palliative care for salvage treatment, with improved survival with chemotherapy [38].

Overall survival has the advantage of being unambiguous (the patient is dead or alive). Assessing the distribution of survival duration in a group of patients makes use of probability theory and not simple mortality rate. The main disadvantages of this are the impact of subsequent treatment on overall survival and, in the case of long-term survival, the follow-up duration and the risk of loss to follow-up.

In conclusion, an improvement in overall survival or rate of cure is widely accepted as an important goal of lung cancer therapy and is generally considered as the leading criterion of efficacy of a treatment in lung cancer patients.

The subsequent questions are not listed in any particular hierarchical order.

\section{QUESTION 1: CAN THE CRITERIA OF PFS, TTP AND DFS BE USED TO ASSESS OVERALL SURVIVAL?}

PFS is defined as the duration between registration or randomisation in a study and the first objective aggravation of the disease or death. TTP is the time from study enrolment to the first date of disease progression. DFS is the period between registration or randomisation in a study and tumour recurrence or death. This criterion is mainly used in the adjuvant and surgical settings when no more target lesions are available [39].

To date, two meta-analyses have been published assessing the predictive value of TTP on overall survival in lung cancer patients $[40,41]$. A pooled analysis of selected randomised controlled trials was orally presented during the 2008 American Society of Clinical Oncology (ASCO) meeting [42]. Although not published in full, it was selected for the present guidelines because detailed results and methodology were available on the ASCO website. The results of these three studies are reported in table 3 . The three studies dealt with advanced NSCLC treated with first-line chemotherapy in randomised controlled trials. In the two published studies [40,41], a statistically significant correlation between TTP and overall survival was detected, although it was of limited amplitude. In the study reported by HоттA et al. [41], the median TTP ratio accounted for less than half the variability (41\%) of the median survival ratio. To predict a statistically significant improvement in the survival time at the p-value of 0.05 , an increase in the median TTP of 1.8 months must be observed for trials with 750 patients, and 2.2 months and 3.3 months for those with 500 and 250 patients, respectively [40]. Some evidence for a relationship between PFS and overall survival is provided in the latter study [42]: a $30 \%$ reduction in the risk of progression assessed by PFS predicts a statistically significant effect on overall survival in patients with advanced NSCLC treated with firstline docetaxel- or vincalcaloid-containing regimens. It must be pointed out that this positive association between improved PFS and further increase in survival was recently not confirmed in randomised trials comparing chemotherapy to epidermal growth factor receptor tyrosine kinase inhibitors (TKIs), despite a high hazard ratio for PFS favouring the TKI treatment [43-45].

We did not find meta-analyses or specific studies with, as their primary objective, the assessment of PFS, TTP or DFS as an intermediate marker for overall survival in resectable NSCLC treated by surgery with or without chemotherapy, in unresectable NSCLC treated by chemoradiotherapy, in NSCLC receiving salvage chemotherapy, and in SCLC.

TABLE 3 Meta-analyses or pooled analysis assessing the role of time-to-progression and progression-free survival as intermediate end-point for overall survival in lung cancer patients

\begin{tabular}{|c|c|c|c|c|c|c|c|}
\hline Reference & End-point & Population & $\begin{array}{l}\text { Considered } \\
\text { studies }\end{array}$ & Period & $\begin{array}{c}\text { Studies } \\
\mathbf{n}\end{array}$ & $\begin{array}{c}\text { Patients } \\
\text { n }\end{array}$ & $\begin{array}{l}\text { Relationship between } \\
\text { the intermediate criteria } \\
\text { and overall survival }\end{array}$ \\
\hline JoHnson et al. [40] & TTP & $\begin{array}{l}\text { Advanced } \\
\text { NSCLC }\end{array}$ & $\begin{array}{c}\text { RCT } \\
\text { of first line CT }\end{array}$ & 1966-2005 & 191 & 44125 & $\begin{array}{c}r^{2}=0.19 \\
p=0.0003\end{array}$ \\
\hline HоттA et al. [41] & $\begin{array}{l}\text { Median } \\
\text { TTP ratio }\end{array}$ & $\begin{array}{l}\text { Advanced } \\
\text { NSCLC }\end{array}$ & $\begin{array}{l}\text { Phase III RCT } \\
\text { of first line CT }\end{array}$ & 1987-2002 & 54 & 23457 & $\begin{array}{l}\text { Multivariate analysis } \\
\qquad \begin{array}{c}r^{2}=0.33 \\
p<0.01\end{array}\end{array}$ \\
\hline Buyse et al. [42] & PFS & $\begin{array}{l}\text { Advanced } \\
\text { NSCLC }\end{array}$ & $\begin{array}{c}\text { RCT } \\
\text { of first line } \mathrm{CT}^{\#}\end{array}$ & 2003-2006 & 7 & 2838 & $\begin{array}{l}\text { Multivariate analysis } \\
\qquad r^{2}=0.61\end{array}$ \\
\hline
\end{tabular}

TTP: time-to-progression; NSCLC: nonsmall cell lung cancer; RCT: randomised controlled trial; CT: chemotherapy; PFS: progression-free survival. ${ }^{\#}$ : RCT comparing docetaxel to vincalcaloids regimens. 
PFS, TTP and DFS have potential advantages in prospective studies, by reducing the number of patients to be accrued, and the follow-up and study durations, as well as in alleviating the effect of subsequent treatment on the study end-point. There are numerous disadvantages related to the parameters used, as follows. Which is the best criterion determining objective progression? How do you consider disagreements on evaluation criteria among investigators? How do you manage the absence of blinding in interpretation of results? Most importantly, all these parameters are highly dependent on the duration between two disease assessments and the type of assessment, which must be independent of the treatment arm.

\section{Recommendations}

1) TTP is an intermediate marker for overall survival in advanced NSCLC treated with first-line chemotherapy. Level of evidence: meta-analyses; quality of evidence: 3; grade of recommendation: Fs.

2) PFS is a potential intermediate marker for survival in the setting of docetaxel or vinca-alcaloid first-line regimens. Level of evidence: meta-analyses; quality of evidence: 2; grade of recommendation: Fw.

\section{Statements}

More evidence is needed to confirm that TTP or PFS and DFS are intermediate criteria predicting overall survival in the following settings: in patients with resectable NSCLC treated by surgery with or without chemotherapy, with unresectable NSCLC treated by chemoradiotherapy, with NSCLC treated by salvage chemotherapy and with SCLC. DFS cannot be recommended as an intermediate marker for overall survival, owing to the lack of data.

\section{QUESTION 2: IS OBJECTIVE MORPHOLOGICAL RESPONSE TO CHEMOTHERAPY A VALID EFFICACY CRITERION, AND WHICH EVALUATION CRITERIA FOR RESPONSE ARE TO BE USED?}

The first definition of objective response was proposed by C.G. Zubrod in 1960. Currently, three systems are available (table 4).
All are based on expert opinions without adequate statistical methodology applied for choosing the cut-off determining the different categories of response. The WHO system was published in 1979 [14]. The South West Oncology Group (SWOG) used its own definition, close to that of the WHO, in its studies [46]. RECIST (Response Evaluation Criteria In Solid Tumours) was developed in 2000, to be used in clinical studies [47]. The main differences between RECIST and WHO/SWOG criteria were the following: use of unidimensional instead of bidimensional measurement, limitation in the number of target lesions (maximum five per organ with an overall maximum of 10 lesions), and different cut-offs for response and progression. A new version of RECIST has recently been published [48]. The main modifications of version 1.1 are that a maximum of two lesions per organ are considered and that a complete response on lymph nodes is defined as a node no more than $10 \mathrm{~mm}$ in short axis.

Seven meta-analyses have been published to date that assess, as the primary objective of the study, the relationship between objective response to chemotherapy and survival [40, 49-54]. Objective response and/or disease control (objective response plus stable disease) predict improvement in overall survival in the following situations: advanced NSCLC receiving first-line or salvage chemotherapy and extensive disease SCLC treated by first-line chemotherapy (table 5). In three meta-analyses, the impact of response on overall survival was quantified. A statistically significant $(\mathrm{p}<0.05)$ increase in overall survival could be observed for an increase in response rate of $18 \%$ requiring 750 patients to be included in randomised trials. This value increases to $21 \%$ and $30 \%$ if the number of patients is 500 or 250 , respectively [40]. In two other studies, each $1 \%$ increase in response rate resulted in an improvement in median survival time of 0.26 months in patients receiving TKI [54] or 0.07 months with salvage chemotherapy [51]. When specified, the evaluation criteria for response were most often those of the WHO and RECIST. However, no formal comparison between the two systems has been performed for lung cancer patients. We also looked at large retrospective studies pooling

\begin{tabular}{|c|c|c|c|}
\hline \multirow[t]{2}{*}{ TABLE 4} & \multirow[b]{2}{*}{ WHO } & \multirow[b]{2}{*}{ SWOG } & T (Response Evaluation Criteria In \\
\hline & & & RECIST $^{\#}$ \\
\hline Complete response & $\begin{array}{l}\text { Complete disappearance of all } \\
\text { measurable and assessable tumoural } \\
\text { lesions not less than } 4 \text { weeks apart }\end{array}$ & $\begin{array}{c}\text { Complete disappearance of all measurable and } \\
\text { assessable tumoural lesions, including normalisation } \\
\text { of markers and other abnormal laboratory values for } \\
\text { at least 3-6 weeks }\end{array}$ & $\begin{array}{l}\text { Complete disappearance of all tumoural } \\
\text { lesions for at least } 4 \text { weeks }\end{array}$ \\
\hline Partial response & $\begin{array}{l}\text { Decrease } \geqslant 50 \% \text { of the product of } \\
\text { the two greatest perpendicular } \\
\text { diameters for at least } 4 \text { weeks }\end{array}$ & $\begin{array}{l}\text { Decrease } \geqslant 50 \% \text { of the product of the two greatest } \\
\text { perpendicular diameters for at least } 3-6 \text { weeks }\end{array}$ & $\begin{array}{l}\text { Decrease } \geqslant 30 \% \text { of the sum of } \\
\text { the greatest diameters }\end{array}$ \\
\hline Stable disease & No response or progression & $\begin{array}{c}\text { Decrease }<50 \% \text { or increase }<50 \%\left(<10 \mathrm{~cm}^{2}\right) \text { of the } \\
\text { product of the two greatest diameters for at least } 3-6 \\
\text { weeks }\end{array}$ & No response or progression \\
\hline
\end{tabular}


TABLE 5 Meta-analyses assessing response as an intermediate marker for overall survival in lung cancer

\begin{tabular}{|c|c|c|c|c|}
\hline \multicolumn{5}{|c|}{ NSCLC treated by chemotherapy ${ }^{\#}$} \\
\hline \multirow[t]{2}{*}{ TsuJino et al. [54] } & 6171 & OR: $p<0.0001$ ( $\uparrow$ MST 0.26 month $/ \uparrow 1 \%$ OR) & $U$ & WHO, RECIST \\
\hline & & DCR: $p=0.003(\uparrow$ MST 0.17 month $/ \uparrow 1 \%$ DCR $)$ & & \\
\hline \multicolumn{5}{|c|}{ Advanced NSCLC receiving first line chemotherapy } \\
\hline HotтA et al. [50] & & DCR: $r=0.08(p<0.0001)$ & & \\
\hline SHANAFELT et al. [53] & 2794 & OR: $r^{2}=0.22(\uparrow$ MST 1 week $/ \uparrow 3.3 \%$ OR $)$ & $U$ & \\
\hline \multicolumn{5}{|c|}{ NSCLC receiving salvage chemotherapy } \\
\hline \multirow[t]{2}{*}{ HotTA et al. [50] } & 4318 & OR: $p=0.69$ & M & \\
\hline & & DCR: $p=0.013$ & & \\
\hline
\end{tabular}

prospective trials performed for lung cancer (table 6) [55-58]. Objective response was also found to be a significant predictor for better survival in advanced and metastatic NSCLC [55-57] and in SCLC [58], whatever the stage of the disease, treated by chemotherapy.

No meta-analyses or randomised trials having the evaluation of response as an intermediate criterion for survival were available in the following clinical settings: induction chemotherapy for operable NSCLC, sequential or concomitant chemoradiotherapy for locoregionally advanced NSCLC, and limited disease and recurrent SCLC. Better survival was found in patients with NSCLC presenting with an objective response to induction chemotherapy before surgery or to treatment for locoregionally advanced NSCLC, induction chemotherapy before radiotherapy, chemoradiotherapy, or radiotherapy alone [59-64]. The level of evidence was from analyses of secondary objectives of randomised trials published on each topic (table 6) and phase II studies [66-74]. We found only one study in SCLC showing that patients with complete response had longer survival than those with partial response or no change, those progressing under firstline treatment with chemotherapy or chemoradiotherapy having the worst prognosis [65].

There are few formal comparisons allowing determination of which evaluation criteria are to be used. In the RECIST publication [47], a comparison between RECIST 1.0 and WHO criteria did not find any significant difference for assessing objective response or progression, whether considering the whole population or only lung cancer patients. Further studies have been performed in patients with lung cancer, which are summarised in table 7. Overall, there was no significant difference between the two systems of evaluation for response determination [47, 75-79].

\section{Recommendations}

1) Objective response is an intermediate criterion for overall survival in advanced NSCLC treated with first-line or salvage chemotherapy. Level of evidence: meta-analyses and randomised trials; quality of evidence: 4; grade of recommendation: Fs.

2) Objective response is an intermediate criterion for overall survival in extensive disease SCLC treated with first-line chemotherapy. Level of evidence: meta-analyses and retrospective studies; quality of evidence: 2; grade of recommendation: Fw.

3) Objective response is a potential intermediate criterion for overall survival in operable NSCLC treated with induction chemotherapy and in locoregionally advanced NSCLC treated by chemotherapy and radiotherapy. Level of evidence: retrospective studies; quality of evidence: 2; grade of recommendation: Fw.

\section{Statements}

More evidence is needed to confirm that objective response is an intermediate criterion predicting overall survival in the following settings: operable NSCLC treated with induction chemotherapy, locoregionally advanced NSCLC and limited disease SCLC treated by chemotherapy and radiotherapy.

WHO and RECIST 1.0 criteria appear to have the same efficacy in predicting objective response in locoregionally advanced and metastatic NSCLC. On the basis of the available data, it is not possible to determine the best response criterion to be used in other settings related to lung cancer management, the equivalence of WHO and RECIST criteria having to be confirmed in larger studies.

The cut-off point to define response/progression, as proposed by the WHO and the RECIST systems, needs validation assessment. 


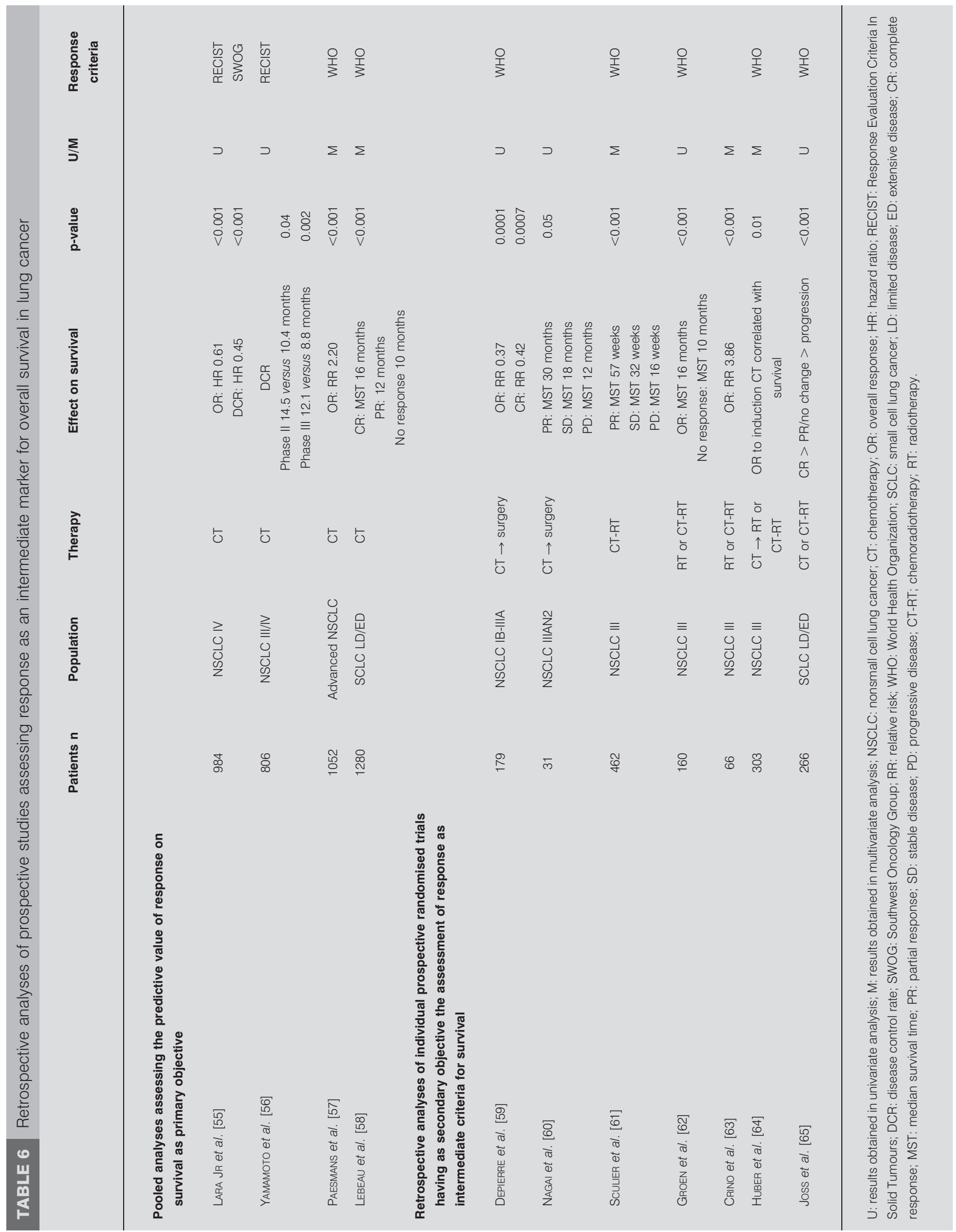




\begin{tabular}{|c|c|c|c|c|c|c|c|c|}
\hline \multirow{2}{*}{$\begin{array}{l}\text { TABLE } 7 \\
\text { Study }\end{array}$} & \multicolumn{8}{|c|}{$\begin{array}{l}\text { Comparison between World Health Organization (WHO) and RECIST (Response Evaluation Criteria In Solid Tumours) } \\
1.0 \text { for response assessment in lung cancer }\end{array}$} \\
\hline & & $\mathbf{P} / \mathbf{R}$ & Patients n & Population & RR-RECIST\% & RR-WHO\% & PD-RECIST\% & PD-WHO\% \\
\hline \multicolumn{2}{|c|}{ THERASSE et al. [47] } & $\mathrm{R}$ & 1197 & ND & 32 & 32 & & \\
\hline \multicolumn{2}{|c|}{ WERNER-WASIK et al. [75] } & $P$ & 22 & Locally advanced NSCLC & 87 & 87 & & \\
\hline \multicolumn{2}{|c|}{ CoRTES et al. [76] } & $\mathrm{R}$ & 164 & Metastatic NSCLC & 52 & 52 & 26 & 26 \\
\hline \multicolumn{2}{|c|}{ PARK et al. [78] } & $\mathrm{R}$ & 28 & NSCLC & 39 & 43 & 25 & 29 \\
\hline \multicolumn{2}{|c|}{ KoNISHI et al. [79] } & $\mathrm{R}$ & 32 & & 38 & 47 & 6 & 6 \\
\hline
\end{tabular}

In the context of maintenance therapy, disease control rate (response plus stable disease) needs validation assessment.

\section{QUESTION 3: ARE OBJECTIVE MORPHOLOGICAL AND METABOLIC RESPONSE CRITERIA AND LOCAL CONTROL APPLICABLE TO ASSESS OVERALL SURVIVAL IN THE CASE OF CHEMORADIOTHERAPY (EITHER SEQUENTIAL OR CONCOMITANT)?}

There are many problems when defining response by conventional criteria (WHO and/or RECIST) due to pneumonitis and fibrosis modifications induced by thoracic irradiation, which must be differentiated from residual neoplastic tissue. As these changes are time-related and increase by the use of radiosensitising chemotherapeutic agents, timing of evaluation after treatment could influence response assessment.

The role of new evaluation techniques like PET(-CT) was assessed in a few small retrospective studies. In 73 NSCLC patients treated by radical radiotherapy or chemoradiotherapy, there was poor agreement between PET and CT response assessment (kappa 0.35) using respectively European Organization for Research and Treatment of Cancer (EORTC) and WHO criteria. In multivariate analysis, only PET response was associated with survival $(\mathrm{p}<$ 0.0001) [80]. In a second study including 50 patients treated with induction chemoradiotherapy, followed by surgery in 37 cases, change in standardised uptake value (SUV) on PET-CT after induction treatment was not related to survival $(p=0.75)$ [81]. Lastly, SUVmax after induction chemoradiotherapy predicted survival in operated patients with NSCLC. The median survival was longer for the patients with SUVmax $<4$ than in those with SUV more than 4, namely, 56 months versus 19 months $(p<0.001)$ [82].

Local control is another commonly used approach to undertake intrathoracic response assessment. In a consensus expert conference held in Bruges, Belgium in 1993, the proposals for defining lung cancer local control after thoracic irradiation were complete disappearance of all radiographic abnormalities by chest film CT and residual radiographic abnormality assessed by chest CT at 3 and 6 months, which then remains stable for an additional 6 months or more. This definition has never been the topic of a validation study.

Literature on this question is relatively disappointing. We found only a few retrospective studies or secondary analyses of randomised trials assessing the association between local control and survival in lung cancer. BIRCH et al. [83] observed for limited disease SCLC that survival was longer for patients achieving local control after chemoradiotherapy than for those who did not. In a small retrospective study including limited and extensive disease SCLC, COx et al. [84] had the same observation. DOSORETz et al. [85] showed that local control resulted in improved survival in irradiated medically inoperable NSCLC. In a retrospective study of Radiation Therapy Oncology Group randomised trials, local control was associated with significantly better survival [86]. However, the ELCWP could not confirm these results in a phase III trial comparing chemotherapy to chemotherapy followed by radiotherapy in stage III unresectable NSCLC [87]. A significant increase in local control duration was obtained in the combination arm: median of 158 weeks versus 31 weeks, with respective 2 -yr rates of $57 \%$ and $24 \%(p=0.0007)$. This better local control duration did not result in a statistically significant increase in survival duration: median of 54 weeks (95\% CI 43-73 weeks) versus 42 weeks (95\% CI $35-51$ weeks), with 2-yr survival rates of $22 \%$ (95\% CI $11-$ $33 \%$ ) and $18 \%$ (95\% CI 8-28\%).

\section{Recommendations}

1) Although commonly used, conventional criteria for response assessment of primary lung tumours treated by (chemo) radiotherapy cannot be used as intermediate criteria for survival. Level of evidence: retrospective studies; quality of evidence: 1; grade of recommendation: Aw.

2) Local control, for which the definition has to be clarified, is a possible intermediate criterion for overall survival. Level of evidence: retrospective studies; quality of evidence: 1; grade of recommendation: Fw.

\section{Statement}

The roles of conventional WHO or RECIST criteria, of metabolic response criteria (PET imaging) and of local control as intermediate criteria in the context of lung cancer treated by (chemo)radiotherapy have to be assessed in prospective studies.

\section{QUESTION 4: CAN QUALITY OF LIFE CRITERIA BE USED TO PREDICT OVERALL SURVIVAL? WHICH QUALITY OF LIFE SCORING SYSTEM HAS TO BE APPLIED?}

We identified some data in the literature related to this topic, although there are many papers suggesting a prognostic role for baseline QoL data [88-90]. Several scoring systems exist and have been validated with the availability of modules dedicated to lung cancer symptoms and treatment sideeffects. Those which have been studied in association with the 
predictive value of QoL on other outcomes (response to chemotherapy, PFS and survival) are the EORTC QoL core questionnaire (30 items) complemented by the lung cancer module LC13 [91, 92] and the Functional Assessment of Cancer Therapy - Lung (FACT-L) with a module specific for the symptoms of the disease (LCSS) [93]. Before looking at this predictive value, it is relevant to define what is meant by a response at the QoL level. OsOBA et al. [94] defined an increase in the overall EORTC QoL score of $>10$ points as a response, a decrease of $>10$ points as a progression, and intermediate results as stabilisation, on the basis of concordance between QoL score evolution and a subjective question. CELLA et al. [95] proposed a definition of response for two outcomes for the LCSS score (from 0 to 28, with increasing values for increasing QoL) and the TOI (Trial Outcome Index, which is the sum of LCSS and functional and physical wellbeing scales, from 0 to 84). For the first outcome, an increase of 2-3 points is needed and, for the TOI, an increase of $5-7$ points is required. Definitions of stabilisation and progression are derived from these thresholds. This proposal resulted from the analysis of a clinical trial and used the association between QoL evolution and response to chemotherapy or PFS.

One report on a meta-analysis suggests that an association between QoL and radiological response exists (positive correlation), but this meta-analysis was not dedicated to lung cancer and suffered from a serious selection bias: out of more than 350 studies identified by the literature search, only 21 could be included in the quantitative review [96].

EтON et al. [97] have shown, for patients with advanced lung cancer, using the database of a clinical trial and the FACT-L scoring system, that classification into four groups (I: high baseline FACT-L score with improvement; II: high baseline with deterioration; III: low baseline with improvement; IV: low baseline with deterioration) has prognostic value for TTP and overall survival. Group I had the best results, followed by group II, group III and group IV $(\mathrm{p}<0.001)$.

CELLA et al. [98] studied the QoL evolution among patients treated in the IRESSA Dose Evaluation in Advanced Lung Cancer (IDEAL)-2 trial testing gefitinib as second-line treatment for NSCLC. The patients with a QoL response ( $>2$ point improvement on the LCSS scale) had a significantly prolonged survival compared with the other patients (median of 13 months compared with 5 months after a landmark of 8 weeks; $\mathrm{p}<0.001$ ). Data from IDEAL-1 point in the same direction [99]. In the Iressa NSCLC Trial Assessing Combination Treatment (INTACT) trials looking at the addition of gefitinib to a chemotherapy regimen in the first-line setting, the association between QoL and antitumoural response has been studied using the EORTC QoL questionnaire. The associations with different scales (overall scale, physical scale, pain, cough and dyspnoea) and response were all significant. However, we do not have any available data about the value of QoL response for PFS or overall survival [100, 101].

\section{Recommendation}

Response at the QoL level cannot be recommended as an intermediate criterion for overall survival owing to a lack of robust data. Level of evidence: retrospective studies; quality of evidence: 1; grade of recommendation: Aw.

\section{Statement}

The association between response at the QoL level and long-term outcomes, as suggested in some instances (recurrent NSCLC treated with gefitinib), needs further investigation, including adequate determination of cut-off points defining a response, and of the most appropriate questionnaire.

\section{QUESTION 5: CAN DOWNSTAGING AFTER INDUCTION CHEMO(RADIO)THERAPY PREDICT OVERALL SURVIVAL, AND WHICH ASSESSMENT METHODOLOGY NEEDS TO BE USED?}

Downstaging can be defined as a shift to a lower disease stage after a treatment. In NSCLC, studies assessing the prognostic role of downstaging on survival after induction chemotherapy have been performed at the mediastinal ( $\mathrm{N}$ stage) or the TN level. The literature is generally heterogeneous. Inclusion criteria are quite different from one study to another according to stage, mediastinal evaluation (clinical or pathological definition), type of treatment (induction chemotherapy or chemoradiotherapy before surgery; nonsurgical treatment only) and type of downstaging ( $\mathrm{N}$ or $\mathrm{TN})$. Most of the publications are case series or retrospective analyses of phase II studies of small sample size. We found only two phase III trials in which these questions were retrospectively analysed. The first trial compared the role of surgery to radiotherapy in stage IIIA pathological N2 NSCLC treated by induction chemotherapy [102]. In the surgery arm including 154 randomised patients, mediastinal downstaging was an independent prognostic factor for survival in multivariate analysis $(\mathrm{p}=0.04)$. In the second trial, comparing chemoradiotherapy alone to chemoradiotherapy followed by surgery in stage III pathological N2 NSCLC, mediastinal downstaging in the surgical group (164 patients) was associated with better survival in univariate analysis with median survival times for pathological N0 and N1-3 of 34.4 months and 26.4 months, respectively $(\mathrm{p}<0.0001)$ [103].

Mediastinal downstaging in NSCLC has been assessed by noninvasive (CT and PET scan), minimally invasive (oesophageal (EUS) or endobronchial (EBUS) endoscopic procedures), and invasive procedures (re-mediastinoscopy and video-assisted thoracoscopic surgery (VATS)). In its 2007 guidelines, the European Society of Thoracic Surgeons did not recommend a particular procedure for restaging but recommended that cytohistological proof be obtained by a minimally invasive or invasive procedure, depending on the availability and specific expertise of staff at the centre [104]. The literature on mediastinal restaging was recently reviewed [105]. Sensitivity, specificity, false-negative and false-positive rates for mediastinal CT restaging were on average $63 \%, 70 \%, 31 \%$ and $34 \%$, respectively. Respective values for PET scan were $63 \%, 70 \%, 26 \%$ and $34 \%$. Combined PET-CT seems more adequate, with sensitivity of $62-77 \%$, specificity of $88-92 \%$, false-negative rate of $20-25 \%$, false-positive rate of $7-$ $25 \%$, and an accuracy of $79-83 \%[106,107]$. Few studies have assessed the role of minimally invasive procedures for mediastinal re-staging. EUS was evaluated in three very small studies, EBUS in one, and transbronchial needle aspiration in another. Average sensitivity and false-negative rates were $84 \%$ and $14 \%$, respectively. Re-mediastinoscopy is technically challenging due to adherence and fibrosis. In a few studies, the sensitivity of this technique was $63 \%$, with $100 \%$ specificity and accuracy of $84-93 \%$. The false-negative rate was $22 \%$. VATS was assessed in a small 
series of 70 patients [108]. The procedure was unsuccessful in 17 patients owing to fibrosis. Reported sensitivity, specificity and negative predictive value were $75 \%, 100 \%$ and $76 \%$, respectively.

\section{Recommendation}

Although not strictly demonstrated, there are numerous assertions from subgroup analyses of randomised trials and retrospective studies that mediastinal downstaging and, to a lesser extent, TN downstaging are associated with better survival in locally advanced NSCLC treated by induction chemotherapy or chemoradiotherapy before surgery. Level of evidence: retrospective studies; quality of evidence: 2; grade of recommendation: Fw.

\section{Statements}

The association between downstaging after induction chemotherapy (or chemoradiotherapy) and long-term outcomes should be confirmed and needs further investigation in adequately powered prospective studies.

PET-CT is the recommended noninvasive technique for mediastinal restaging, being more precise than CT scan, which appears insufficiently accurate in this setting. When pre-operative pathological persistent mediastinal neoplastic infiltration has to be confirmed, minimally invasive or invasive techniques are feasible, each one appearing with similar efficacy. The choice of the technique will depend on the local expertise and the initial technique used for demonstrating mediastinal invasion.

\section{QUESTION 6: DO COMPLETE RESECTION AND PATHOLOGICAL TNM HAVE A PREDICTIVE ROLE FOR SURVIVAL?}

The basis of the definition of complete resection is the Union Internationale Contre le Cancer (UICC) residual tumour classification (R classification) [109]. R0 category consists of the absence of residual tumour in the primary site, lymph nodes and distant sites, which appears insufficient in lung cancer, and is mainly for the mediastinal definition of complete resection. The Complete Resection subcommittee of the International Association for the Study of Lung Cancer (IASLC) Staging Committee, after an extensive review of the literature, proposed the definition of complete resection based on an international consensus [110]: "Complete resection requires all of the following: free resection margins proved microscopically; systematic nodal dissection or lobe-specific systematic nodal dissection; no extracapsular nodal extension of the tumour; and the highest mediastinal node removed must be negative. Whenever there is involvement of resection margins, extracapsular nodal extension, unremoved positive lymph nodes, or positive pleural or pericardial effusions, the resection is defined as incomplete. When the resection margins are free and no residual tumour is left, but the resection does not fulfil the criteria for complete resection, there is carcinoma in situ at the bronchial margin, or positive pleural lavage cytology, the term uncertain resection is proposed." R1 is defined as a persistence of microscopic tumour tissue and R2 as macroscopic incomplete resection.

The level of evidence of the prognostic role of R0 in NSCLC is relatively low. There have been many studies derived from retrospective analyses of phase II and surgical series, mainly including stage IIIA-N2 NSCLC. In most of them, R0 was a predictive factor for survival in either univariate or multivariate analysis. We found only one phase III trial in which R0 was evaluated in multivariate analysis as a secondary end-point [102]. In 154 stage IIIAN2 NSCLC patients receiving induction chemotherapy followed by surgery, R0 was an independent prognostic factor for survival with median survival times of 24 (R0) versus 12 months (R1/R2). For a few large series, including pathological stage I-IV NSCLC patients, incomplete resection was reported as a poor prognostic factor for survival in multivariate analysis. Involved resection margins were associated with an increased risk of death (hazard ratio 1.49; $p<0.001$ ) among 3,211 patients from a Norwegian registry [111]. In another surgical series of 836 patients, a hazard ratio of $8.2(\mathrm{p}<0.001)$ was observed in R1/R2 in comparison with R0 cases [112]. Doubling or tripling of the risk of death was observed in a series of 446 patients $(\mathrm{p}<0.01)$ [113].

The IASLC reported the largest recent studies, assessing the prognostic role of pathologic TNM in 9137 resected NSCLC. In multivariate analysis, pathological stage using the seventh version proposed by the IASLC was a significant prognostic factor for survival $(p<0.0001)$ [114]. In large series or registry studies of more than 500 patients, pTNM [111, 115-117] and, when analysed separately, $\mathrm{pT}$ or $\mathrm{pN}[112,118,119]$, were found to be independently associated with survival. Lastly, pTNM, pT, or $\mathrm{pN}$ was found to be a significant predictor for survival in six randomised trials assessing the role of adjuvant chemotherapy after surgery and considering pathological stage in analyses of prognostic factors [120-125]. In these studies, the fifth version of the UICC and American Joint Committee on Cancer Staging system was most often used, although the fourth version was applied in three studies.

\section{Recommendations}

1) Complete resection is a prognostic factor for survival in resected NSCLC and can be used as an intermediate criterion for overall survival. Level of evidence: cohort and retrospective studies; quality of evidence: 3; grade of recommendation: Fs.

2) Pathological TNM is a prognostic factor for survival in resected NSCLC and can be used as an intermediate criterion for overall survival. Level of evidence: cohort studies; quality of evidence: 3; grade of recommendation: Fs.

\section{Statement}

The definition of complete resection proposed by the Complete Resection subcommittee of the IASLC is recommended.

\section{QUESTION 7: CAN METABOLIC RESPONSE, ASSESSED BY ${ }^{18}$ F-FLUORODEOXYGLUCOSE GATHERING ON POSITRON EMISSION TOMOGRAPHY $\left({ }^{18}\right.$ F-FDG-PET OR PET-CT), PREDICT THE EFFICACY OF CHEMOTHERAPY?}

In a systematic review of the literature with a meta-analysis $[126,127]$, primary tumour SUVmax measured on ${ }^{18}$ F-FDG-PET has been shown to have prognostic value in NSCLC. This observation needs to be confirmed by a multivariate analysis taking into account the known prognostic factors; nevertheless, it strongly suggests than PET may be more useful than only providing imaging.

PET has been proposed for the assessment of response to chemotherapy. Criteria were defined in 1999 by the EORTC PET 
Study Group [128]. A complete metabolic response is complete resolution of ${ }^{18} \mathrm{~F}$-FDG uptake within the tumour volume so that it is indistinguishable from surrounding normal tissue. A partial metabolic response consists of the reduction of a minimum of $15 \%$ in tumour SUV after one cycle of chemotherapy, and greater than $25 \%$ after more than one treatment cycle. A reduction in the extent of the tumour uptake is not a requirement for partial metabolic response. A stable metabolic disease is an increase in tumour SUV $<25 \%$ or a decrease $<15 \%$ and no visible increase in the extent of tumour uptake (20\% in the longest dimension). A progressive metabolic disease consists of an increase in tumour SUV $>25 \%$ within the tumour region defined on the baseline scan, visible increase in the extent of tumour uptake $(20 \%$ in the longest dimension), or appearance of new FDG uptake in metastatic lesions. For the experts, $25 \%$ was found to be a useful cut-off point, but there was a need for reproducibility analysis to determine the appropriate cut-off for statistical significance. 10 yrs later, that analysis has yet to be performed.

Data on lung cancer in this context are limited and heterogeneous. A few small studies have assessed the predictive effect of metabolic response for further survival. In a series of 57 patients with advanced NSCLC treated by chemotherapy, changes in SUV have been shown to have relatively similar adequacy to changes in tumour/muscle ratio and to be better than changes in netinflux constants [129]. In another series of 51 NSCLC patients (15 treated by induction chemotherapy and 31 by palliative chemotherapy), metabolic response assessed by the EORTC criteria was not associated with a significant difference in survival, while it became significant when patients were divided into two groups according to the median change in SUV [130]. In a group of 30 patients with stage IIIAN2 NSCLC treated by induction chemotherapy, the best cut-off in decrease of SUVmax to predict 5 -yr survival was $60 \%$; a decrease of $25 \%$ was not discriminatory [131]. In a systematic review of the literature about the prediction of histopathological response and further survival in stage III disease treated by induction treatment, DE GEUS-OEI et al. [132] showed the great heterogeneity of studies in terms of cut-off of SUV used and definition of pathologic response. In the series reported above, Dooms et al. [131] defined a group with good prognosis by combining pathological ( $\mathrm{pN} 0$ or $\mathrm{pN} 2$ with $<10 \%$ cancer cells in mediastinal lymph nodes) and metabolic $(>60 \%$ decrease of SUV max in the primary tumour) criteria. Finally, complete (but not partial) metabolic response has been associated with better survival in a series of 31 stage III NSCLC patients [133].

The predictive effect of initial SUVmax of the primary tumour for morphological response to chemotherapy has been the topic of one paper on advanced NSCLC (87 patients) [134]. SUVmax (dichotomised by the median) was the single significant predictor in univariate and multivariate analyses, but the patients with high SUVmax had shorter duration of response and there was no overall difference in survival between patients with high and low SUVmax.

The early assessment of the metabolic response after the first course of chemotherapy has been investigated in two small studies, suggesting some potential utility for predicting further survival [135, 136].

Studies of the prediction of morphological response by the metabolic response have been described in two reports. In the first one, the metabolic response was shown to have high predictive value $(96 \%)$, meaning that, if PET scan does not show a response, it is very unlikely for one to be documented by morphological tests [129]. The positive predictive value is, however, not very good $(71 \%)$. In the second study, performed on 89 patients, the correlation between metabolic response (either visual or based on SUVmax) and morphological response was poor and the SUVmax measured after chemotherapy did not predict further survival [73]. We also have to take into account potential methodological problems due to the lack of standardisation.

\section{Recommendation}

Metabolic response assessed by PET scan should not be used for the routine assessment of response to treatment in lung cancer patients in place of morphological criteria. Level of evidence: retrospective studies and case series; quality of evidence: 1; grade of recommendation: Aw.

\section{Statements}

The cut-off point of $25 \%$ to define response/progression, as proposed by the EORTC for metabolic response, needs validation assessment.

Metabolic response requires further investigation with strict methodology in terms of PET scan examination standardisation, morphological response assessment, and outcome definition.

\section{QUESTION 8: WHAT IS THE ROLE OF TISSUE BIOLOGICAL MARKERS FOR THE EVALUATION OF OVERALL SURVIVAL?}

Numerous biomarkers have been tested in lung cancer for prognostic purposes or for predicting response to chemotherapy or radiotherapy. Determination of the presence or absence of a tissue biomarker can be performed by various techniques (immunohistochemistry, PCR, fluorescence in situ hybridisation and high-throughput techniques, etc.) that assess cancer biology at different levels: protein expression, RNA or DNA abnormalities. The question is whether differential expression of tissue biomarkers during treatment, before and after chemotherapy for example, could reliably predict treatment efficacy and overall survival.

Many studies on tissue biomarkers in lung cancer have been published. They have looked at the prognostic role for survival of these biological markers, usually obtained at initial diagnosis, mainly in NSCLC surgical series. To a lesser extent, their predictive role for treatment sensitivity was studied. However, we found only one published study assessing the relationship between the modifications of tissue biomarkers during therapy and overall survival [137]. 54 patients with stage III NSCLC were treated by induction chemotherapy followed by concomitant chemoradiotherapy, and surgery if the tumour became resectable. There was no difference in the apoptotic indices before and after neoadjuvant treatment and no statistically significant impact on survival was observed.

One potential explanation of the lack of studies is related to the difficulties in easily obtaining adequate tissue samples in lung cancer patients. This problem is yet more pronounced when a good response is observed and no surgery is planned. 


\section{Recommendation}

Tissue biological markers should not be used for evaluation of treatment efficacy and are not adequate intermediate criteria for overall survival in lung cancer patients. Level of evidence: case series; quality of evidence: 1; grade of recommendation: Aw.

\section{Statements}

The role of tissue biological markers in assessing overall survival in lung cancer needs further investigation with adequate methodology; that is, in terms of positivity definition, and standardisation in the evaluation methods and statistical methodology (multivariate analysis taking into account known prognostic factors).

\section{QUESTION 9: WHAT IS THE ROLE OF CIRCULATING MARKERS (MOLECULES OR CELLS) FOR THE ASSESSMENT OF OVERALL SURVIVAL?}

We aimed to determine if modification in the levels of circulating markers before and after therapeutic procedures in lung cancer patients can reliably predict overall survival. We selected the markers as described in the methodology section. We also specifically searched for biological markers known as potential prognostic factors in either NSCLC or SCLC: lactate dehydrogenase, alkaline phosphatases, white cell and neutrophil counts, platelet count, haemoglobinaemia, natraemia, calcaemia, bilirubinaemia, cyfra 21-1, carcinoembryonic antigen (CEA), neuronespecific enolase (NSE), pro-gastrin releasing peptide (pro-GRP), and other cancer markers such as CA19-9 and CA-125. Publications were eligible if the correlation between the marker and overall survival was assessed.

Although the prognostic role for survival of the selected variables taken at initial diagnosis has been extensively studied, few studies, summarised in table 8 , have been published that assess the prognostic role on survival of their expression before and after treatment [138-141, 143, 144, 146-153]. Criteria used by the authors to define response based on the levels of circulating markers were variable, allowing only indirect comparisons between studies. It must be pointed out that, of these studies, the majority was retrospective.

Post-therapy CEA normalisation or significant decrease seems to be related to better survival in early stage NSCLC treated by surgery [138, 140-142], in advanced NSCLC with chemotherapy $[139,143]$, and after salvage gefitinib in relapsing NSCLC [144]. Cyfra 21-1 decrease has been reported to be significantly associated with improved survival in two studies [139, 143] while no association was observed in a third [146]. For other factors, it could be suggested from small studies that decreases

TABLE 8 Studies assessing the relationship between modification of circulating markers levels after treatment and survival in lung cancer

\begin{tabular}{|c|c|c|c|c|c|c|c|c|}
\hline Study & $\mathbf{P} / \mathbf{R}$ & Marker & Patients $\mathbf{n}$ & Population & Therapy & Effect on survival & p-value & $\mathbf{U} / \mathbf{M}$ \\
\hline OKADA et al. [138] & $\mathrm{R}$ & CEA & 1000 & $\mathrm{NSCLC} \mathrm{cl}$ & Surgery & $\downarrow$ for high post-surgical level & $<0.0001$ & M \\
\hline Nisman et al. [139] & $P$ & CEA & 45 & Advanced NSCLC & CT & $\uparrow$ if $\downarrow \geqslant 35 \%$ & 0.04 & $U$ \\
\hline SAWABATA et al. [140] & $\mathrm{R}$ & CEA & 19 & ADC I & Surgery & $\downarrow$ for high post-surgical level & 0.006 & $U$ \\
\hline SAWABATA et al. [141] & $\mathrm{R}$ & CEA & 242 & NSCLC IA & Surgery & $\downarrow$ for high post-surgical level & $<0.0001$ & M \\
\hline SAWABATA et al. [142] & $\mathrm{R}$ & CEA & 297 & NSCLC cl & Surgery & $\downarrow$ for high post-surgical level & 0.002 & M \\
\hline BRÉCHOT et al. [143] & $P$ & CEA & 116 & NSCLC I-IV & Various & $\uparrow$ if $\downarrow \geqslant 50 \%$ & 0.006 & $U$ \\
\hline CHIU et al. [144] & $\mathrm{R}$ & CEA & 89 & Relapsing NSCLC & Gefitinib & $\uparrow$ if $\downarrow \geqslant 50 \%$ at 4 weeks & 0.03 & $U$ \\
\hline SPIRIDONIDIS et al. [145] & $\mathrm{R}$ & $\begin{array}{c}\text { CEA, CA19-9, } \\
\text { CA-125 }\end{array}$ & 36 & NSCLC I-IIIB & CT or CT-RT & $\uparrow$ if $\downarrow$ if decrease & 0.0002 & $U$ \\
\hline Nisman et al. [139] & $\mathrm{P}$ & Cyfra 21-1 & 45 & Advanced NSCLC & CT & $\uparrow$ if $\downarrow \geqslant 35 \%$ & 0.01 & M \\
\hline HAMZAOUI et al. [146] & $?$ & Cyfra 21-1 & 63 & NSCLC/SCLC III-IV & СT & $\uparrow$ if $\downarrow \geqslant 70 \%$ & 0.44 & $U$ \\
\hline BRÉCHOT et al. [143] & $\mathrm{P}$ & Cyfra 21-1 & 116 & NSCLC I-IV & Various & $\uparrow$ if $\downarrow \geqslant 50 \%$ & 0.0001 & M \\
\hline SunAGA et al. [147] & $\mathrm{R}$ & Pro-GRP & 29 & SCLC I-IV & CT & $\uparrow$ if $\downarrow \geqslant 50 \%$ & 0.001 & M \\
\hline OKUSAKA et al. [148] & $\mathrm{R}$ & Pro-GRP & 18 & SCLC in PR & CT & $\uparrow$ if return to normal & $<0.05$ & $U$ \\
\hline BRÉCHOt et al. [143] & $P$ & NSE & 116 & NSCLC I-IV & Various & $\uparrow$ if $\downarrow \geqslant 50 \%$ & 0.018 & $U$ \\
\hline FIZAZI et al. [149] & $\mathrm{R}$ & NSE & 135 & SCLC LD/ED & CT-RT, CT & $\uparrow$ if return to normal & 0.02 & M \\
\hline BRÉCHOt et al. [143] & $P$ & CA-125 & 116 & NSCLC I-IV & Various & $\uparrow$ if $\downarrow \geqslant 50 \%$ & 0.0006 & $U$ \\
\hline CHIU et al. [144] & $\mathrm{R}$ & CA-125 & 89 & Relapsing NSCLC & Gefitinib & No effect & 0.12 & $U$ \\
\hline CHIU et al. [144] & $\mathrm{R}$ & CA19-9 & 89 & Relapsing NSCLC & Gefitinib & $\uparrow$ if $\downarrow \geqslant 25 \%$ at 8 weeks & $<0.0001$ & $U$ \\
\hline GAUTHIER et al. [150] & $\mathrm{R}$ & Anaemia & 242 & NSCLC IB-II & Surgery + CT & No effect & 0.06 & $U$ \\
\hline LAURIE et al. [151] & $\mathrm{R}$ & Anaemia & 652 & SCLC LD & CT-RT & No effect & 0.33 & $U$ \\
\hline ISHIKAWA et al. [152] & $P$ & СТС & 74 & Relapsing NSCLC & Gefitinib & $\begin{array}{c}\uparrow \text { if ratio T0/T2w or } \\
\text { TO/T4W }<1.2\end{array}$ & $\begin{array}{l}0.002 \\
0.004\end{array}$ & $U$ \\
\hline CHEN et al. [153] & $P$ & CTC & 67 & NSCLC I-IIIB & CT-RT & Persistence of CTC & $<0.001$ & M \\
\hline YAMASHITA et al. [154] & $P$ & СТC & 103 & NSCLC I-IIIA & Surgery & Persistence of CTC & NS & $M$ \\
\hline
\end{tabular}

P: prospective study; R: retrospective study; U: results obtained in univariate analysis; $\mathrm{M}$ : results obtained in multivariate analysis; CEA: carcinoembryonic antigen; NSCLC: nonsmall cell lung cancer; CT: chemotherapy; ADC: adenocarcinoma; CT-RT: chemoradiotherapy; SCLC: small cell lung cancer; pro-GRP: pro-gastrin releasing peptide; PR: partial remission; NSE: neurone-specific enolase; LD: limited disease; ED: extensive disease; CTC: circulating tumour cells; NS: statistically nonsignificant. 
in the following in terms of blood levels were predictive of better survival: pro-GRP in SCLC, CA19-9 in relapsing NSCLC, CA-125 in NSCLC, and NSE in NSCLC and SCLC [143, 144, 147-149]. Anaemia occurring during chemotherapy or chemoradiotherapy has not been demonstrated to have prognostic significance in two larger studies on NSCLC and SCLC [150, 151]. Lastly, the persistence of circulating tumour cells in blood was of prognostic significance in locoregional NSCLC treated by chemoradiotherapy and in relapsing NSCLC treated with gefitinib [152-154].

\section{Recommendations}

1) Some circulating markers (CEA, Cyfra 21-1, pro-GRP and, to a lesser extent, NSE, CA-125, and CA19-9), used as single criterion to assess overall survival, could be adequate intermediate criteria for survival in lung cancer patients. Level of evidence: retrospective studies; quality of evidence: 2; grade of recommendation: Fw.

2) The persistence of circulating tumour cells in NSCLC may have a prognostic impact on further survival. Level of evidence: cohort studies; quality of evidence: 1; grade of recommendation: Fw.

\section{Statement}

The suggested role of circulating markers in assessing overall survival in lung cancer needs further prospective investigation with adequate methodology (including the cut-off determination), that is, in terms of statistical methodology (multivariate analysis taking into account known prognostic factors).

\section{CONCLUSIONS}

Overall survival, or healing for curable disease, is the leading criterion of efficacy of a treatment in lung cancer patients. Intermediate criteria are potential or adequate surrogates for survival, despite some limitations: TTP, PFS, objective response, local chest control after radiotherapy, mediastinal and TNM downstaging in locally advanced NSCLC after induction therapy before surgery, complete resection and pathological TNM in resected NSCLC, and a few circulating markers (CEA, Cyfra 21-1, pro-GRP and, to a lesser extent, NSE, CA-125, and CA19-9). At the present time, some criteria cannot be used for predicting overall survival in lung cancer (and therefore certainly not as surrogates for overall survival): conventional criteria for radiotherapy response assessment of primary lung tumour, quality of life evolution under treatment, metabolic response assessment by FDG-PET scan, and tissue biological markers. The recommendations in this study highlight the need for well-designed prospective studies in many instances where intermediate criteria are of possible interest.

\section{POTENTIAL LIMITATIONS AND PROBLEMS Literature biases}

First, we searched for prospective studies and meta-analyses looking, as the primary objective, at the association between intermediate criteria and overall survival. This approach was recently discussed by BUYSE [155] to demonstrate a possible association between a surrogate and a clinical end-point, requiring data from multiple randomised trials or meta-analyses. In most instances considered in these guidelines, this literature was lacking. Secondly, we searched for secondary end-points of prospective studies and retrospective series. Although we used multiple keywords for each topic and an extensive literature search system (Ovid), it is possible that some studies and series in which some of the selected criteria were actually reported as secondary end-points were not retrieved. However, the impact of this literature bias on the conclusions of these guidelines seems limited as the level of evidence of this type of study is relatively weak (low or very low grade of evidence according to the GRADE system). Furthermore, the inclusion of nonrandomised studies should induce biases in the interpretation of the literature results for assessing association between criteria like determination of objective response and survival. Another potential source of bias is related to the considered languages. We only took into account reports written in English, French, German and Dutch languages that were comprehensible by all of the authors. It must be underlined that most of the results came from clinical trials in which patients were strictly selected and do not fully represent the population treated in routine practice.

\section{Validation studies}

Although we found some statistical associations between intermediate criteria and survival in meta-analyses and small-sized randomised studies, validation studies are required before definite conclusions can be drawn in most instances. These studies need to be prospectively designed with the primary objective being the determination of the relationship between the considered surrogate and the true end-point. They have to consider the clinical value of the association when the effect of the intermediate criterion in predicting survival accounts for only a limited part of the variability of the survival ratio, as we observed with TTP $[40,41]$. The potential surrogate may have a substantial noise component due to issues in defining the intermediate criterion or other factors that may affect the clinical outcome. Therefore, there are some issues concerning the application of a surrogate in situations other than those in which the surrogacy was asserted. These require knowledge about the relevant biological variables whereby the treatment or the considered populations may affect the outcome of primary interest.

\section{Grades of recommendations}

In order to grade the guidelines, the ELCWP has chosen the GRADE system. This internationally accepted grading system for recommendations has previously been used for lung cancer by the American College of Chest Physicians [156]. GRADE has certain advantages. It allows grading of recommendations based on the level of scientific evidence, which is further modulated by the quality of the literature (table 1). It also allows integration into the grade of the recommendations of some subjective variables, such as the balance between desirable and undesirable effects, and the values and preferences or the costs (resource allocation), by guideline writers, which may be of importance in routine practice but cannot always be derived from the literature.

\section{Impact of supplementary treatment on overall survival}

We selected studies assessing a possible relationship between a surrogate and overall survival. Preceding or subsequent therapeutics after the investigated treatment can impact on overall survival and, potentially, on the relationship with the intermediate criteria. Unfortunately, in light of the currently available data, it was not possible to avoid this potential bias in our literature interpretation. 


\section{PERSPECTIVES}

We found that validation of intermediate criteria as surrogate end-points in lung cancer has not really been achieved; furthermore, such a validation may be dependent on the treatment category considered and the population of patients included in the trial. The development of new therapies leads us to consider the use of intermediate criteria to assess their effectiveness in order to achieve possible reductions in sample size, study duration or cost. A further set of intermediate outcomes based on data from gene expression or proteomic platforms will be proposed in the near future. In this context, the identification of a set of intermediate outcomes may be important, taking into account the fact that biological pathways could influence the beneficial or harmful effects of the treatment, influencing the final outcome.

To convincingly validate these early markers as surrogates, a strict methodology has to be developed. Some recommendations have already been proposed by BUYSE and co-workers $[8,155]$ on the use of meta-analyses for validation of clinical surrogates and biomarkers.

\section{STATEMENT OF INTEREST}

Statements of interest for J.J. Lafitte and V. Westeel can be found at www.erj.ersjournals.com/site/misc/statements.xhtml

\section{ACKNOWLEDGEMENTS}

Author affiliations are as follows. T. Berghmans, I. Cs Toth, E. Markiewicz, A.P. Meert, C. Wachters and J.P. Sculier: Dept of Intensive Care and Thoracic Oncology, Institut Jules Bordet, Université Libre de Bruxelles, Brussels, Belgium; F. Pasleau: Bibliothèques des Sciences de la Vie, Université de Liège, Liège, Belgium; M. Paesmans: Data Centre, Institut Jules Bordet, Université Libre de Bruxelles, Brussels, Belgium; Y. Bonduelle: Dept of Pneumology, CH Peltzer-La Tourelle, Verviers, Belgium; J. Cadranel: Dept of Pneumology, Hôpital Tenon, AP-HP, Université Pierre et Marie Curie, Paris, France; C. Garcia: Dept of Nuclear Medicine, Institut Jules Bordet, Université Libre de Bruxelles, Brussels, Belgium; V. Giner: Dept of Medical Oncology, Hospital de Sagunto, Valencia, Spain; S. Holbrechts: Dept of Medical Oncology, Hôpital Ambroise Paré, Mons, Belgium; J.J. Lafitte and A. Scherpereel: Dept of Pneumology, CHRU de Lille, Hôpital Albert Calmette, Lille, France; J. Lecomte: Dept of Pneumology, CHU de Charleroi, Charleroi, Belgium; I. Louviaux: Dept of Medical Oncology, CH Peltzer-La Tourelle, Verviers, Belgium; M. Richez: Dept of Pneumology, CHR St-Joseph-Warquignies, Boussu, Belgium; M. Roelandts and P. Van Houtte: Dept of Radiology, Institut Jules Bordet, Université Libre de Bruxelles, Brussels, Belgium; Ch. Tulippe: Dept of Pneumology, Centre Hospitalier de Mouscron, Mouscron, Belgium; P. Van Schil: Dept of Thoracic and Vascular Surgery, UZ Antwerpen, Antwerp, Belgium; V. Westeel: Dept of Pneumology, CHU de Besançon, Besançon, France.

\section{REFERENCES}

1 Meert AP, Sculier JP. What has the meta-analysis contributed to today's standard of care in the treatment of thoracic malignancies? Lung Cancer 2008; 61: 141-151.

2 European Lung Cancer Working Party. Traitement des cancers bronchiques non à petites cellules résécables. Recommandations de pratique clinique de l'European Lung Cancer Working Party [Management of resectable non-small cell lung cancer. Guidelines of clinical practice made by the European Lung Cancer Working Party]. Rev Med Brux 2006; 27: 29-38.

3 European Lung Cancer Working Party. Traitement des cancers bronchiques non à petites cellules, non métastatiques et non résécable. Recommandations de pratique clinique de l'European
Lung Cancer Working Party [Management of unresectable nonmetastatic non-small cell lung cancer. Guidelines of clinical practice made by the European Lung Cancer Working Party]. Rev Med Brux 2006; 27: 152-161.

4 European Lung Cancer Working Party. Les recommandations de pratique clinique de l'European Lung Cancer Working Party. Cancers bronchiques non à petites cellules: III. Maladies avancées (métastatiques) [Treatment of non-small cell lung cancer: advanced (metastatic) disease. Guidelines of clinical practice made by the European Lung Cancer Working Party]. Rev Med Brux 2007; 28: 495-511.

5 European Lung Cancer Working Party. Traitement du cancer bronchique à petites cellules: maladies limitées. Les recommandations de pratique clinique de l'European Lung Cancer Working Party [Treatment of small cell lung cancer: limited diseases. Guidelines of clinical practice made by the European Lung Cancer Working Party]. Rev Med Brux 2008; 29: 159-167.

6 European Lung Cancer Working Party. Traitement du cancer bronchique à petites cellules: maladies étendues. Les recommandations de pratique clinique de l'European Lung Cancer Working Party [Treatment of small cell lung cancer: extensive diseases. Guidelines of clinical practice made by the European Lung Cancer Working Party]. Rev Med Brux 2008; 29: 455-470.

7 Prentice RL. Surrogate endpoints in clinical trials, definition and operational criteria. Stat Med 1989; 8: 431-440.

8 Buyse M, Sargent DJ, Grothey A, et al. Biomarkers and surrogate end points-the challenge of statistical validation. Nat Rev Clin Oncol 2010; 7: 309-317.

9 Sackett DL, Straus SE, Richardson WS, et al. Evidence-Based Medicine. How to Practice and Teach EBM. Asking Answerable Clinical Questions. 2nd Edn. Edinburgh, Churchill Livingstone, 2000; pp. 13-27.

10 Mountain CF. A new international staging system for lung cancer. Chest 1986; 89: 225S-233S.

11 Mountain CF. Revisions in the International System for Staging Lung Cancer. Chest 1997; 111: 1710-1717.

12 Atkins D, Best D, Briss PA, et al. Grading quality of evidence and strength of recommendations. BMJ 2004; 328: 1490.

13 US Department of Health and Human Services, Food and Drug Administration, Center for Drug Evaluation and Research (CDER). Guidance for Industry. Clinical Trials Endpoints For the Approval of Cancer Drugs and Biologics. Rockville, Food and Drug Administration, 2007.

14 World Health Organization. WHO Handbook for Reporting Results of Cancer Treatment. Geneva, World Health Organization, 1979.

15 Warren W. Historical facets of thoracic surgery emphasizing lung cancer. In: Gruhn JG, Rosen ST, eds. Lung Cancer. The Evolution of Concepts. New York, Field and Wood, 1989; pp. 73-106.

16 Berghmans T, Paesmans M, Meert AP, et al. Survival improvement in resectable non-small cell lung cancer with (neo)adjuvant chemotherapy: results of a meta-analysis of the literature. Lung Cancer 2005; 49: 13-23.

17 Gilligan D, Nicolson M, Smith I, et al. Preoperative chemotherapy in patients with resectable non-small cell lung cancer: results of the MRC LU22/NVALT 2/EORTC 08012 multicentre randomised trial and update of systematic review. Lancet 2007; 369: 1929-1937.

18 Damstrup L, Poulsen HS. Review of the curative role of radiotherapy in the treatment of non-small cell lung cancer. Lung Cancer 1994; 11: 153-178.

19 Jassem J. The role of radiotherapy in lung cancer: where is the evidence? Radiother Oncol 2007; 83: 203-213.

20 Chemotherapy in non-small cell lung cancer: a meta-analysis using updated data on individual patients from 52 randomised clinical trials. Non-small Cell Lung Cancer Collaborative Group. BMJ 1995; 311: 899-909. 
21 Sculier JP, Berghmans T, Paesmans M, et al. La place de la chimiotherapie dans le traitement des cancers bronchiques non a petites cellules, non metastatiques [The role of chemotherapy in the treatment of non-metastatic, non-small cell bronchial cancers]. Rev Med Brux 2001; 22: 477-487.

22 Rakovitch E, Tsao M, Ung Y, et al. Comparison of the efficacy and acute toxicity of weekly versus daily chemoradiotherapy for non-small-cell lung cancer: a meta-analysis. Int J Radiat Oncol Biol Phys 2004; 58: 196-203.

23 Marino P, Preatoni A, Cantoni A. Randomized trials of radiotherapy alone versus combined chemotherapy and radiotherapy in stages IIIa and IIIb nonsmall cell lung cancer. A meta-analysis. Cancer 1995; 76: 593-601.

24 Pritchard RS, Anthony SP. Chemotherapy plus radiotherapy compared with radiotherapy alone in the treatment of locally advanced, unresectable, non-small-cell lung cancer. A metaanalysis. Ann Intern Med 1996; 125: 723-729.

25 Auperin A, Le PC, Pignon JP, et al. Concomitant radiochemotherapy based on platin compounds in patients with locally advanced non-small cell lung cancer (NSCLC): a metaanalysis of individual data from 1764 patients. Ann Oncol 2006; 17: 473-483.

26 Souquet PJ, Chauvin F, Boissel JP, et al. Polychemotherapy in advanced non small cell lung cancer: a meta-analysis. Lancet 1993; 342: 19-21.

27 Grilli R, Oxman AD, Julian JA. Chemotherapy for advanced nonsmall-cell lung cancer: how much benefit is enough? J Clin Oncol 1993; 11: 1866-1872.

28 Marino P, Pampallona S, Preatoni A, et al. Chemotherapy vs supportive care in advanced non-small-cell lung cancer. Results of a meta-analysis of the literature. Chest 1994; 106: 861-865.

29 Sculier JP, Berghmans T, Castaigne A, et al. Best supportive care or chemotherapy for stage IV non small cell lung cancer. In: VanHoutte P, Klastersky J, Rocmans P, eds. Progress and Perspectives in Lung Cancer. Berlin, Springer Verlag, 1999; pp. 199-207.

30 Shepherd FA, Dancey J, Ramlau R, et al. Prospective randomized trial of docetaxel versus best supportive care in patients with non-small-cell lung cancer previously treated with platinumbased chemotherapy. J Clin Oncol 2000; 18: 2095-2103.

31 Shepherd FA, Rodrigues PJ, Ciuleanu T, et al. Erlotinib in previously treated non-small-cell lung cancer. N Engl J Med 2005; 353: 123-132.

32 Green RA, Humphrey E, Close $\mathrm{H}$, et al. Alkylating agents in bronchogenic carcinoma. Am J Med 1969; 46: 516-525.

33 Mascaux C, Paesmans M, Berghmans T, et al. A systematic review of the role of etoposide and cisplatin in the chemotherapy of small cell lung cancer with methodology assessment and meta-analysis. Lung Cancer 2000; 30: 23-36.

34 Pujol JL, Carestia L, Daures JP. Is there a case for cisplatin in the treatment of small-cell lung cancer? A meta-analysis of randomized trials of a cisplatin-containing regimen versus a regimen without this alkylating agent. Br J Cancer 2000; 83: 8-15.

35 Warde P, Payne D. Does thoracic irradiation improve survival and local control in limited-stage small-cell carcinoma of the lung? A meta-analysis. J Clin Oncol 1992; 10: 890-895.

36 Luce S, Paesmans M, Berghmans T, et al. Revue critique des etudes randomisees evaluant le role de la radiotherapie thoracique adjuvante a la chimiotherapie dans le traitement du cancer bronchique a petites cellules au stade limite [Critical review of the randomized trials assessing the role of adjuvant thoracic irradiation and chemotherapy in the treatment of limited-stage small cell lung cancer]. Rev Mal Respir 1998; 15: 633-641.

37 Pignon JP, Arriagada R, Ihde DC, et al. A meta-analysis of thoracic radiotherapy for small-cell lung cancer. $N$ Engl J Med 1992; 327: 1618-1624.
38 O'Brien ME, Ciuleanu TE, Tsekov $\mathrm{H}$, et al. Phase III trial comparing supportive care alone with supportive care with oral topotecan in patients with relapsed small-cell lung cancer. J Clin Oncol 2006; 24: 5441-5447.

39 Effets des anticancéreux sur la durée de survie: souvent mal évalués [Effect of anticancer drugs on survival duration: frequently poorly assessed]. La Revue Prescrire 2009; 29: 218-221.

40 Johnson KR, Ringland C, Stokes BJ, et al. Response rate or time to progression as predictors of survival in trials of metastatic colorectal cancer or non-small-cell lung cancer: a meta-analysis. Lancet Oncol 2006; 7: 741-746.

41 Hotta K, Fujiwara Y, Matsuo K, et al. Time to progression as a surrogate marker for overall survival in patients with advanced non-small cell lung cancer. J Thorac Oncol 2009; 4: 311-317.

42 Buyse ME, Squifflet $\mathrm{P}$, Laporte $\mathrm{S}$, et al. Prediction of survival benefits from progression-free survival in patients with advanced non small cell lung cancer: evidence from a pooled analysis of 2,838 patients randomized in 7 trials. J Clin Oncol 2008; 26: Suppl. 15, 428S.

43 Maemondo $\mathrm{M}$, Inoue A, Kobayashi $\mathrm{K}$, et al. Gefitinib or chemotherapy for non-small-cell lung cancer with mutated EGFR. N Engl J Med 2010; 362: 2380-2388.

44 Mitsudomi T, Morita S, Yatabe Y, et al. Gefitinib versus cisplatin plus docetaxel in patients with non-small-cell lung cancer harbouring mutations of the epidermal growth factor receptor (WJTOG3405): an open label, randomised phase 3 trial. Lancet Oncol 2010; 11: 121-128.

45 Mok TS, Wu YL, Thongprasert S, et al. Gefitinib or carboplatinpaclitaxel in pulmonary adenocarcinoma. N Engl J Med 2009; 361: 947-957.

46 Green S, Weiss GR. Southwest Oncology Group standard response criteria, endpoint definitions and toxicity criteria. Invest New Drugs 1992; 10: 239-253.

47 Therasse P, Arbuck SG, Eisenhauer EA, et al. New guidelines to evaluate the response to treatment in solid tumours. European Organization for Research and Treatment of Cancer, National Cancer Institute of the United States, National Cancer Institute of Canada. J Natl Cancer Inst 2000; 92: 205-216.

48 Eisenhauer EA, Therasse $\mathrm{P}$, Bogaerts $\mathrm{J}$, et al. New response evaluation criteria in solid tumours: revised RECIST guideline (version 1.1). Eur J Cancer 2009; 45: 228-247.

49 Hotta K, Kiura K, Fujiwara Y, et al. Association between incremental gains in the objective response rate and survival improvement in phase III trials of first-line chemotherapy for extensive disease small-cell lung cancer. Ann Oncol 2009; 20: 829-834.

50 Hotta K, Fujiwara Y, Kiura K, et al. Relationship between response and survival in more than 50,000 patients with advanced nonsmall cell lung cancer treated with systemic chemotherapy in 143 phase III trials. J Thorac Oncol 2007; 2: 402-407.

51 Kurata T, Matsuo K, Takada M, et al. Is the importance of achieving stable disease different between epidermal growth factor receptor tyrosine kinase inhibitors and cytotoxic agents in the second-line setting for advanced non-small cell lung cancer? J Thorac Oncol 2006; 1: 684-691.

52 Sekine I, Kubota K, Nishiwaki Y, et al. Response rate as an endpoint for evaluating new cytotoxic agents in phase II trials of non-small-cell lung cancer. Ann Oncol 1998; 9: 1079-1084.

53 Shanafelt TD, Loprinzi C, Marks R, et al. Are chemotherapy response rates related to treatment-induced survival prolongations in patients with advanced cancer? J Clin Oncol 2004; 22: 1966-1974.

54 Tsujino K, Kawaguchi T, Kubo A, et al. Response rate is associated with prolonged survival in patients with advanced non-small cell lung cancer treated with gefitinib or erlotinib. J Thorac Oncol 2009; 4: 994-1001. 
55 Lara PN Jr, Redman MW, Kelly K, et al. Disease control rate at 8 weeks predicts clinical benefit in advanced non-small-cell lung cancer: results from Southwest Oncology Group randomized trials. J Clin Oncol 2008; 26: 463-467.

56 Yamamoto N, Nambu Y, Fujimoto T, et al. A landmark point analysis with cytotoxic agents for advanced NSCLC. J Thorac Oncol 2009; 4: 697-701.

57 Paesmans M, Sculier JP, Libert P, et al. Response to chemotherapy has predictive value for further survival of patients with advanced non-small cell lung cancer: 10 years experience of the European Lung Cancer Working Party. Eur J Cancer 1997; 33: 2326-2332.

58 Lebeau B, Chastang C, Schuller MP, et al. Chimiotherapie des cancers bronchiques a petites cellules. Importance pronostique d'une reponse complete (1,280 patients). Groupe Petites Cellules [Chemotherapy of small cell bronchial cancers. Prognostic importance of complete response (1,280 patients). Groupe Petites Cellules]. Presse Med 1995; 24: 217-221.

59 Depierre A, Milleron B, Moro-Sibilot D, et al. Preoperative chemotherapy followed by surgery compared with primary surgery in resectable stage I (except T1N0), II, and IIIa nonsmall-cell lung cancer. J Clin Oncol 2002; 20: 247-253.

60 Nagai K, Tsuchiya R, Mori T, et al. A randomized trial comparing induction chemotherapy followed by surgery with surgery alone for patients with stage IIIA N2 non-small cell lung cancer (JCOG 9209). J Thorac Cardiovasc Surg 2003; 125: 254-260.

61 Sculier JP, Paesmans M, Lafitte JJ, et al. Prognostic factors analysis for response to chemotheray and survival in a prospective cohort of patients with unresectable locoregional non small cell lung cancer initially treated by induction chemotherapy. Rev Oncologia 1999; 1: 92-100.

62 Groen HJ, van der Leest AH, Fokkema E, et al. Continuously infused carboplatin used as radiosensitizer in locally unresectable non-small-cell lung cancer: a multicenter phase III study. Ann Oncol 2004; 15: 427-432.

63 Crino L, Latini P, Meacci M, et al. Induction chemotherapy plus high-dose radiotherapy versus radiotherapy alone in locally advanced unresectable non-small-cell lung cancer. Ann Oncol 1993; 4: 847-851.

64 Huber RM, Flentje M, Schmidt M, et al. Simultaneous chemoradiotherapy compared with radiotherapy alone after induction chemotherapy in inoperable stage IIIA or IIIB non-small-cell lung cancer: study CTRT99/97 by the Bronchial Carcinoma Therapy Group. J Clin Oncol 2006; 24: 4397-4404.

65 Joss RA, Alberto P, Bleher EA, et al. Combined-modality treatment of small-cell lung cancer: randomized comparison of three induction chemotherapies followed by maintenance chemotherapy with or without radiotherapy to the chest. Swiss Group for Clinical Cancer Research (SAKK). Ann Oncol 1994; 5: 921-928.

66 Betticher DC, Hsu Schmitz SF, Totsch M, et al. Prognostic factors affecting long-term outcomes in patients with resected stage IIIA pN2 non-small-cell lung cancer: 5-year follow-up of a phase II study. Br J Cancer 2006; 94: 1099-1106.

67 Comella P, Scoppa G, Daponte A, et al. Alternated approach with local irradiation and combination chemotherapy including cisplatin or carboplatin plus epirubicin and etoposide in intermediate stage non-small cell lung cancer. Cancer 1994; 74: 1874-1881.

68 Lorent N, De Leyn P, Lievens Y, et al. Long-term survival of surgically staged IIIA-N2 non-small-cell lung cancer treated with surgical combined modality approach: analysis of a 7-year prospective experience. Ann Oncol 2004; 15: 1645-1653.

69 Maurel J, Martinez-Trufero J, Artal A, et al. Prognostic impact of bulky mediastinal lymph nodes $(\mathrm{N} 2>2.5 \mathrm{~cm})$ in patients with locally advanced non-small-cell lung cancer (LA-NSCLC) treated with platinum-based induction chemotherapy. Lung Cancer 2000; 30: 107-116

70 Pignon T, Ruggieri S, Boutin C, et al. Alternating chemotherapy and accelerated split-course irradiation in locally advanced nonsmall cell lung carcinoma. Cancer 1999; 85: 2144-2150.

71 Port JL, Korst RJ, Lee PC, et al. Surgical resection for residual N2 disease after induction chemotherapy. Ann Thorac Surg 2005; 79: 1686-1690.

72 Reboul F, Brewer Y, Vincent $\mathrm{P}$, et al. Concurrent cisplatin etoposide, and radiotherapy for unresectable stage III nonsmall cell lung cancer: a phase II study. Int J Radiat Oncol Biol Phys 1996; 35: 343-350.

73 Tanvetyanon T, Eikman EA, Sommers E, et al. Computed tomography response, but not positron emission tomography scan response, predicts survival after neoadjuvant chemotherapy for resectable non-small-cell lung cancer. J Clin Oncol 2008; 26: 4610-4616.

74 Yokomise $\mathrm{H}$, Gotoh $\mathrm{M}$, Okamoto $\mathrm{T}$, et al. Induction chemoradiotherapy (carboplatin-taxane and concurrent 50-Gy radiation) for bulky cN2, N3 non-small cell lung cancer. J Thorac Cardiovasc Surg 2007; 133: 1179-1185.

75 Werner-Wasik M, Xiao Y, Pequignot E, et al. Assessment of lung cancer response after nonoperative therapy: tumour diameter, bidimensional product, and volume. A serial CT scan-based study. Int J Radiat Oncol Biol Phys 2001; 51: 56-61.

76 Cortes J, Rodriguez J, az-Gonzalez JA, et al. Comparison of unidimensional and bidimensional measurements in metastatic non-small cell lung cancer. Br J Cancer 2002; 87: 158-160.

77 Watanabe H, Yamamoto S, Kunitoh H, et al. Tumour response to chemotherapy: the validity and reproducibility of RECIST guidelines in NSCLC patients. Cancer Sci 2003; 94: 1015-1020.

78 Park JO, Lee SI, Song SY, et al. Measuring response in solid tumours: comparison of RECIST and WHO response criteria. Jpn J Clin Oncol 2003; 33: 533-537.

79 Konishi K, Kuriyama K, Chino S, et al. [CT evaluation of response to chemotherapy and/or radiotherapy in primary lung cancer: comparison of response evaluation criteria in solid tumours (RECIST) and the WHO criteria, and comparison of both methods with the histological evaluation]. Nippon Igaku Hoshasen Gakkai Zasshi 2004; 64: 41-45.

80 MacManus MP, Hicks RJ, Matthews JP, et al. Positron emission tomography is superior to computed tomography scanning for response-assessment after radical radiotherapy or chemoradiotherapy in patients with non-small-cell lung cancer. J Clin Oncol 2003; 21: 1285-1292.

81 Pottgen C, Levegrun S, Theegarten D, et al. Value of ${ }^{18} \mathrm{~F}$-fluoro-2deoxy-D-glucose-positron emission tomography/computed tomography in non-small-cell lung cancer for prediction of pathologic response and times to relapse after neoadjuvant chemoradiotherapy. Clin Cancer Res 2006; 12: 97-106.

82 Hellwig D, Graeter TP, Ukena D, et al. Value of F-18-fluorodeoxyglucose positron emission tomography after induction therapy of locally advanced bronchogenic carcinoma. J Thorac Cardiovasc Surg 2004; 128: 892-899.

83 Birch R, Omura GA, Greco FA, et al. Patterns of failure in combined chemotherapy and radiotherapy for limited small cell lung cancer: Southeastern Cancer Study Group experience. NCI Monogr 1988; 6: 265-270.

84 Cox JD, Byhardt R, Komaki R, et al. Interaction of thoracic irradiation and chemotherapy on local control and survival in small cell carcinoma of the lung. Cancer Treat Rep 1979; 63: 1251-1255.

85 Dosoretz DE, Galmarini D, Rubenstein JH, et al. Local control in medically inoperable lung cancer: an analysis of its importance in outcome and factors determining the probability of tumour eradication. Int J Radiat Oncol Biol Phys 1993; 27: 507-516. 
86 Perez CA, Bauer M, Edelstein S, et al. Impact of tumour control on survival in carcinoma of the lung treated with irradiation. Int J Radiat Oncol Biol Phys 1986; 12: 539-547.

87 Sculier JP, Paesmans M, Lafitte JJ, et al. A randomised phase III trial comparing consolidation treatment with further chemotherapy to chest irradiation in patients with initially unresectable locoregional non-small-cell lung cancer responding to induction chemotherapy. European Lung Cancer Working Party. Ann Oncol 1999; 10: 295-303.

88 Moinpour CM, Lyons B, Grevstad PK, et al. Quality of life in advanced non-small-cell lung cancer: results of a Southwest Oncology Group randomized trial. Qual Life Res 2002; 11: 115-126.

89 Efficace F, Bottomley A, Smit EF, et al. Is a patient's self-reported health-related quality of life a prognostic factor for survival in non-small-cell lung cancer patients? A multivariate analysis of prognostic factors of EORTC study 08975. Ann Oncol 2006; 17: 1698-1704.

90 Gotay CC, Kawamoto CT, Bottomley A, et al. The prognostic significance of patient-reported outcomes in cancer clinical trials. J Clin Oncol 2008; 26: 1355-1363.

91 Aaronson NK, Ahmedzai S, Bergman B, et al. The European Organization for Research and Treatment of Cancer QLQ-C30: a quality-of-life instrument for use in international clinical trials in oncology. J Natl Cancer Inst 1993; 85: 365-376.

92 Bergman B, Aaronson NK, Ahmedzai S, et al. The EORTC QLQLC13: a modular supplement to the EORTC Core Quality of Life Questionnaire (QLQ-C30) for use in lung cancer clinical trials. EORTC Study Group on Quality of Life. Eur J Cancer 1994; 30A: 635-642.

93 Cella DF, Bonomi AE, Lloyd SR, et al. Reliability and validity of the Functional Assessment of Cancer Therapy-Lung (FACT-L) quality of life instrument. Lung Cancer 1995; 12: 199-220.

94 Osoba D, Rodrigues G, Myles J, et al. Interpreting the significance of changes in health-related quality-of-life scores. J Clin Oncol 1998; 16: 139-144.

95 Cella D, Eton DT, Fairclough DL, et al. What is a clinically meaningful change on the Functional Assessment of Cancer Therapy-Lung (FACT-L) Questionnaire? Results from Eastern Cooperative Oncology Group (ECOG) Study 5592. J Clin Epidemiol 2002; 55: 285-295.

96 Victorson D, Soni M, Cella D. Metaanalysis of the correlation between radiographic tumour response and patient-reported outcomes. Cancer 2006; 106: 494-504.

97 Eton DT, Fairclough DL, Cella D, et al. Early change in patientreported health during lung cancer chemotherapy predicts clinical outcomes beyond those predicted by baseline report: results from Eastern Cooperative Oncology Group Study 5592. J Clin Oncol 2003; 21: 1536-1543.

98 Cella D, Herbst RS, Lynch TJ, et al. Clinically meaningful improvement in symptoms and quality of life for patients with non-small-cell lung cancer receiving gefitinib in a randomized controlled trial. J Clin Oncol 2005; 23: 2946-2954.

99 Natale RB. Effects of ZD1839 (Iressa, gefitinib) treatment on symptoms and quality of life in patients with advanced nonsmall cell lung cancer. Semin Oncol 2004; 31: 23-30.

100 Herbst RS, Giaccone G, Schiller JH, et al. Gefitinib in combination with paclitaxel and carboplatin in advanced non-small-cell lung cancer: a phase III trial-INTACT 2. J Clin Oncol 2004; 22: 785-794.

101 Giaccone G, Herbst RS, Manegold C, et al. Gefitinib in combination with gemcitabine and cisplatin in advanced non-small-cell lung cancer: a phase III trial-INTACT 1. J Clin Oncol 2004; 22: 777-784.

102 van Meerbeeck JP, Kramer GW, Van Schil PE, et al. Randomized controlled trial of resection versus radiotherapy after induction chemotherapy in stage IIIA-N2 non-small-cell lung cancer. J Natl Cancer Inst 2007; 99: 442-450.
103 Albain KS, Swann RS, Rusch VW, et al. Radiotherapy plus chemotherapy with or without surgical resection for stage III non-small-cell lung cancer: a phase III randomised controlled trial. Lancet 2009; 374: 379-386.

104 De Leyn P, Lardinois D, Van Schil PE, et al. ESTS guidelines for preoperative lymph node staging for non-small cell lung cancer. Eur J Cardiothorac Surg 2007; 32: 1-8.

105 de Cabanyes CS, Detterbeck FC. A systematic review of restaging after induction therapy for stage IIIa lung cancer: prediction of pathologic stage. J Thorac Oncol 2010; 5: 389-398.

106 Cerfolio RJ, Bryant AS, Ojha B. Restaging patients with N2 (stage IIIa) non-small cell lung cancer after neoadjuvant chemoradiotherapy: a prospective study. J Thorac Cardiovasc Surg 2006; 131: 1229-1235.

107 De Leyn P, Stroobants S, De WW, et al. Prospective comparative study of integrated positron emission tomography-computed tomography scan compared with remediastinoscopy in the assessment of residual mediastinal lymph node disease after induction chemotherapy for mediastinoscopy-proven stage IIIAN2 Non-small-cell lung cancer: a Leuven Lung Cancer Group Study. J Clin Oncol 2006; 24: 3333-3339.

108 Jaklitsch MT, Gu L, Harpole DH, et al. Prospective phase II trial of pre-resection thoracoscopic (VATS) restaging following neoadjuvant therapy for IIIA (N2) non-small cell lung cancer (NSCLC) results of CALGB 39803. J Clin Oncol 2005; 23: Suppl. $16,636 \mathrm{~S}$.

109 Wittekind C, Compton CC, Greene FL, et al. TNM residual tumour classification revisited. Cancer 2002; 94: 2511-2516.

110 Rami-Porta R, Wittekind C, Goldstraw P. Complete resection in lung cancer surgery: proposed definition. Lung Cancer 2005; 49: 25-33.

111 Strand TE, Rostad H, Moller B, et al. Survival after resection for primary lung cancer: a population based study of 3211 resected patients. Thorax 2006; 61: 710-715.

112 Suzuki K, Nagai K, Yoshida J, et al. Conventional clinicopathologic prognostic factors in surgically resected nonsmall cell lung carcinoma. A comparison of prognostic factors for each pathologic TNM stage based on multivariate analyses. Cancer 1999; 86: 1976-1984.

113 Martin J, Ginsberg RJ, Venkatraman ES, et al. Long-term results of combined-modality therapy in resectable non-small-cell lung cancer. J Clin Oncol 2002; 20: 1989-1995.

114 Chansky K, Sculier JP, Crowley JJ, et al. The International Association for the Study of Lung Cancer Staging Project: prognostic factors and pathologic TNM stage in surgically managed non-small cell lung cancer. J Thorac Oncol 2009; 4: 792-801.

115 Birim O, Kappetein AP, van Klaveren RJ, et al. Prognostic factors in non-small cell lung cancer surgery. Eur J Surg Oncol 2006; 32: 12-23.

116 Pfannschmidt J, Muley T, Bulzebruck $H$, et al. Prognostic assessment after surgical resection for non-small cell lung cancer: experiences in 2083 patients. Lung Cancer 2007; 55: 371377.

117 Wisnivesky JP, Henschke C, McGinn T, et al. Prognosis of stage II non-small cell lung cancer according to tumour and nodal status at diagnosis. Lung Cancer 2005; 49: 181-186.

118 Gomez de la Cámara A, Lopez-Encuentra A, Ferrando P. Heterogeneity of prognostic profiles in non-small cell lung cancer: too many variables but a few relevant. Eur J Epidemiol 2005; 20: 907-914.

119 Koike T, Tsuchiya R, Goya T, et al. Prognostic factors in 3315 completely resected cases of clinical stage I non-small cell lung cancer in Japan. J Thorac Oncol 2007; 2: 408-413.

120 Ohta M, Tsuchiya R, Shimoyama M, et al. Adjuvant chemotherapy for completely resected stage III non-small-cell lung cancer. 
Results of a randomized prospective study. The Japan Clinical Oncology Group. J Thorac Cardiovasc Surg 1993; 106: 703-708.

121 A randomized trial of postoperative adjuvant chemotherapy in non-small cell lung cancer (the second cooperative study). The Study Group of Adjuvant Chemotherapy for Lung Cancer (Chubu, Japan). Eur J Surg Oncol 1995; 21: 69-77.

122 Wada H, Hitomi S, Teramatsu T. Adjuvant chemotherapy after complete resection in non-small-cell lung cancer. West Japan Study Group for Lung Cancer Surgery. J Clin Oncol 1996; 14: 1048-1054.

123 Wada H, Miyahara R, Tanaka F, et al. Postoperative adjuvant chemotherapy with PVM (Cisplatin + Vindesine + Mitomycin C) and UFT (Uracil + Tegaful) in resected stage I-II NSCLC (nonsmall cell lung cancer): a randomized clinical trial. West Japan Study Group for lung cancer surgery (WJSG). Eur J Cardiothorac Surg 1999; 15: 438-443.

124 Scagliotti GV, Fossati R, Torri V, et al. Randomized study of adjuvant chemotherapy for completely resected stage I, II, or IIIA non-small-cell Lung cancer. J Natl Cancer Inst 2003; 95: 14531461.

125 Douillard JY, Rosell R, De Lena M, et al. Adjuvant vinorelbine plus cisplatin versus observation in patients with completely resected stage IB-IIIA non-small-cell lung cancer (Adjuvant Navelbine International Trialist Association [ANITA]): a randomised controlled trial. Lancet Oncol 2006; 7: 719-727.

126 Berghmans T, Dusart M, Paesmans M, et al. Primary tumour standardized uptake value (SUVmax) measured on fluorodeoxyglucose positron emission tomography (FDG-PET) is of prognostic value for survival in non-small cell lung cancer (NSCLC): a systematic review and meta-analysis (MA) by the European Lung Cancer Working Party for the IASLC Lung Cancer Staging Project. J Thorac Oncol 2008; 3: 6-12.

127 Paesmans M, Berghmans T, Dusart M, et al. Primary tumour standardized uptake value measured on fluorodeoxyglucose positron emission tomography is of prognostic value for survival in non-small cell lung cancer: update of a systematic review and meta-analysis by the European Lung Cancer Working Party for the International Association for the Study of Lung Cancer Staging Project. J Thorac Oncol 2010; 5: 612-619.

128 Young H, Baum R, Cremerius U, et al. Measurement of clinical and subclinical tumour response using $\left[{ }^{18} \mathrm{~F}\right]$-fluorodeoxyglucose and positron emission tomography: review and 1999 EORTC recommendations. European Organization for Research and Treatment of Cancer (EORTC) PET Study Group. Eur J Cancer 1999; 35: 1773-1782.

129 Weber WA, Petersen V, Schmidt B, et al. Positron emission tomography in non-small-cell lung cancer: prediction of response to chemotherapy by quantitative assessment of glucose use. J Clin Oncol 2003; 21: 2651-2657.

130 de Geus-Oei LF, van der Heijden HF, Visser EP, et al. Chemotherapy response evaluation with 18F-FDG PET in patients with non-small cell lung cancer. J Nucl Med 2007; 48: 1592-1598.

131 Dooms C, Verbeken E, Stroobants S, et al. Prognostic stratification of stage IIIA-N2 non-small-cell lung cancer after induction chemotherapy: a model based on the combination of morphometric-pathologic response in mediastinal nodes and primary tumour response on serial 18-fluoro-2-deoxy-glucose positron emission tomography. J Clin Oncol 2008; 26: 1128-1134.

132 de Geus-Oei LF, van der Heijden HF, Corstens FH, et al. Predictive and prognostic value of FDG-PET in nonsmall-cell lung cancer: a systematic review. Cancer 2007; 110: 1654-1664.

133 Decoster L, Schallier D, Everaert H, et al. Complete metabolic tumour response, assessed by 18-fluorodeoxyglucose positron emission tomography $\left({ }^{18} \mathrm{FDG}-\mathrm{PET}\right)$, after induction chemotherapy predicts a favourable outcome in patients with locally advanced non-small cell lung cancer (NSCLC). Lung Cancer 2008; 62: 55-61.
134 Lee KH, Lee SH, Kim DW, et al. High fluorodeoxyglucose uptake on positron emission tomography in patients with advanced non-small cell lung cancer on platinum-based combination chemotherapy. Clin Cancer Res 2006; 12: 4232-4236.

135 Hoekstra CJ, Stroobants SG, Smit EF, et al. Prognostic relevance of response evaluation using $\left[{ }^{18} \mathrm{~F}\right]$-2-fluoro-2-deoxy-D-glucose positron emission tomography in patients with locally advanced non-small-cell lung cancer. J Clin Oncol 2005; 23: 8362-8370.

136 Nahmias C, Hanna WT, Wahl LM, et al. Time course of early response to chemotherapy in non-small cell lung cancer patients with ${ }^{18}$ F-FDG PET/CT. J Nucl Med 2007; 48: 744-751.

137 Junker K, Muller KM, Bosse U, et al. Apoptose und Tumorregression bei neoadjuvant behandelten lokal fortgeschrittenen nichtkleinzelligen Lungenkarzinomen [Apoptosis and tumour regression in locally advanced non-small cell lung cancer with neoadjuvant therapy]. Pathologe 2003; 24: 214-219.

138 Okada M, Nishio W, Sakamoto T, et al. Prognostic significance of perioperative serum carcinoembryonic antigen in non-small cell lung cancer: analysis of 1,000 consecutive resections for clinical stage I disease. Ann Thorac Surg 2004; 78: 216-221.

139 Nisman B, Biran H, Heching N, et al. Prognostic role of serum cytokeratin 19 fragments in advanced non-small-cell lung cancer: association of marker changes after two chemotherapy cycles with different measures of clinical response and survival. $\mathrm{Br} J$ Cancer 2008; 98: 77-79.

140 Sawabata N, Hirano H, Inoue M, et al. Immunohistochemical analysis of resected clinical stage I pulmonary adenocarcinomas with high preoperative levels of serum carcinoembryonic antigen. Ann Thorac Surg 2003; 76: 203-207.

141 Sawabata N, Maeda H, Yokota S, et al. Postoperative serum carcinoembryonic antigen levels in patients with pathologic stage IA nonsmall cell lung carcinoma: subnormal levels as an indicator of favorable prognosis. Cancer 2004; 101: 803-809.

142 Sawabata N, Ohta M, Takeda S, et al. Serum carcinoembryonic antigen level in surgically resected clinical stage I patients with non-small cell lung cancer. Ann Thorac Surg 2002; 74: 174-179.

143 Bréchot JM, Chevret S, Nataf J, et al. Diagnostic and prognostic value of Cyfra 21-1 compared with other tumour markers in patients with non-small cell lung cancer: a prospective study of 116 patients. Eur J Cancer 1997; 33: 385-391.

144 Chiu CH, Shih YN, Tsai CM, et al. Serum tumour markers as predictors for survival in advanced non-small cell lung cancer patients treated with gefitinib. Lung Cancer 2007; 57: 213-221.

145 Spiridonidis CH, Laufman LR, Stydnicki KA, et al. Decline of posttreatment tumour marker levels after therapy of nonsmall cell lung cancer. A useful outcome predictor. Cancer 1995; 75: 1586-1593.

146 Hamzaoui A, Thomas P, Castelnau O, et al. Usefulness of longitudinal evaluation of Cyfra 21-1 variations in advanced lung cancer monitoring. Lung Cancer 1997; 16: 191-202.

147 Sunaga N, Tsuchiya S, Minato K, et al. Serum pro-gastrinreleasing peptide is a useful marker for treatment monitoring and survival in small-cell lung cancer. Oncology 1999; 57: 143-148.

148 Okusaka T, Eguchi K, Kasai T, et al. Serum levels of pro-gastrinreleasing peptide for follow-up of patients with small cell lung cancer. Clin Cancer Res 1997; 3: 123-127.

149 Fizazi K, Cojean I, Pignon JP, et al. Normal serum neuron specific enolase (NSE) value after the first cycle of chemotherapy: an early predictor of complete response and survival in patients with small cell lung carcinoma. Cancer 1998; 82: 1049-1055.

150 Gauthier I, Ding K, Winton T, et al. Impact of hemoglobin levels on outcomes of adjuvant chemotherapy in resected non-small cell lung cancer: the JBR.10 trial experience. Lung Cancer 2007; 55: 357-363.

151 Laurie SA, Ding K, Whitehead M, et al. The impact of anaemia on outcome of chemoradiation for limited small-cell lung cancer: a 
combined analysis of studies of the National Cancer Institute of Canada Clinical Trials Group. Ann Oncol 2007; 18: 1051-1055.

152 Ishikawa $\mathrm{N}$, Hattori N, Yokoyama $\mathrm{A}$, et al. Usefulness of monitoring the circulating Krebs von den Lungen-6 levels to predict the clinical outcome of patients with advanced nonsmall cell lung cancer treated with epidermal growth factor receptor tyrosine kinase inhibitors. Int J Cancer 2008; 122: 2612-2620.

153 Chen TF, Jiang GL, Fu XL, et al. CK19 mRNA expression measured by reverse-transcription polymerase chain reaction (RT-PCR) in the peripheral blood of patients with non-small cell lung cancer treated by chemo-radiation: an independent prognostic factor. Lung Cancer 2007; 56: 105-114.
154 Yamashita J, Matsuo A, Kurusu Y, et al. Preoperative evidence of circulating tumour cells by means of reverse transcriptasepolymerase chain reaction for carcinoembryonic antigen messenger RNA is an independent predictor of survival in non-small cell lung cancer: a prospective study. J Thorac Cardiovasc Surg 2002; 124: 299-305.

155 Buyse M. Use of meta-analysis for the validation of surrogate endpoints and biomarkers in cancer trials. Cancer J 2009; 15: 421-425.

156 Guyatt G, Gutterman D, Baumann MH, et al. Grading strength of recommendations and quality of evidence in clinical guidelines: report from an American College of Chest Physicians task force. Chest 2006; 129: 174-181. 